\title{
The Evolution and Polarization of Public Opinion on Vaccines
}

\author{
David R. Jones \\ Baruch College, CUNY \\ david.jones@,baruch.cuny.edu
}

\author{
Monika L. McDermott \\ Fordham University \\ mmcdermott@,fordham.edu
}

\begin{abstract}
This study reviews tends in available public opinion data on vaccines, which mainly cover 20012021. Four general findings emerge. First, Americans have been progressively hearing more information about vaccines over the past two decades. Second, attitudes regarding vaccines' utility, safety, and appropriateness of requirements have mostly declined during this same period. Third, trends in reported vaccination behavior differ from trends in attitudes, and also vary across different vaccine types. The pattern of these differences suggests a strong influence of public policies on vaccine behavior. Finally, an analysis of trends among Democrats and Republicans suggests that vaccine attitudes and behavior were mostly apolitical up until around 2008 or so. But since then - and clearly prior to the politicization of the COVID-19 pandemic - the parties have increasingly diverged on vaccines. While Republicans have continued to become more vaccine skeptical, Democrats have actually reversed the overall trend and become more vaccine supportive.
\end{abstract}




\section{The Evolution and Polarization of Public Opinion on Vaccines}

This study reviews trends in available public opinion data on vaccines, which mainly cover the two decades from 2001 to 2021 . Many observers speculate this may be the same time period during which vaccine skepticism - bolstered by Andrew Wakefield's infamous 1998 Lancet publication along with more widespread public access to the internet-evolved from being more of a fringe viewpoint to one with greater mainstream support (Hussain, Ali, Ahmed, and Hussain 2018). It is also a period during which partisan conflict has begun to extend itself into areas once thought to be non-partisan, including trust in science (Krause et al 2019), raising the possibility that vaccines themselves have become partisan over time.

We begin by looking at trends in the volume and type of information the public receives about certain vaccines. We then examine perceptions regarding the utility of vaccines, followed by perceptions of vaccine safety. Next, we turn to the topic of support for vaccine requirements. Lastly, we present data on trend in willingness to get vaccinated for different types of illnesses. In addition to looking at opinions of the overall adult population, within each section of the paper where there are appropriate data we also compare trends among Democrats as opposed to Republicans to examine potential partisan polarization in vaccine opinions.

Information on Vaccines

Because people's information environment affects their opinions (Zaller 1992), it is useful to look at the level and type of information Americans report receiving about vaccines. In 2001, 2015 and 2019, Gallup asked Americans how much they had heard about the advantages and about the disadvantages of vaccines for children. Both series show an increase over the course of the eighteenyear period, suggesting that, overall, Americans have been hearing more information about vaccines in recent years (figure 1). 
While the direction of the trend for both series is the same, the magnitude of the change in each is quite different. In 2001, a 74 percent majority of Americans had heard about advantages of childhood vaccines, while only a 39 percent minority had heard of disadvantages - a gap between positive and negative information of 35 points. By 2019, the percentage hearing about advantages rose a modest 15 points, but the percentage hearing about disadvantages rose by a substantial 40 points, narrowing the gap between positive and negative information to only 10 points.

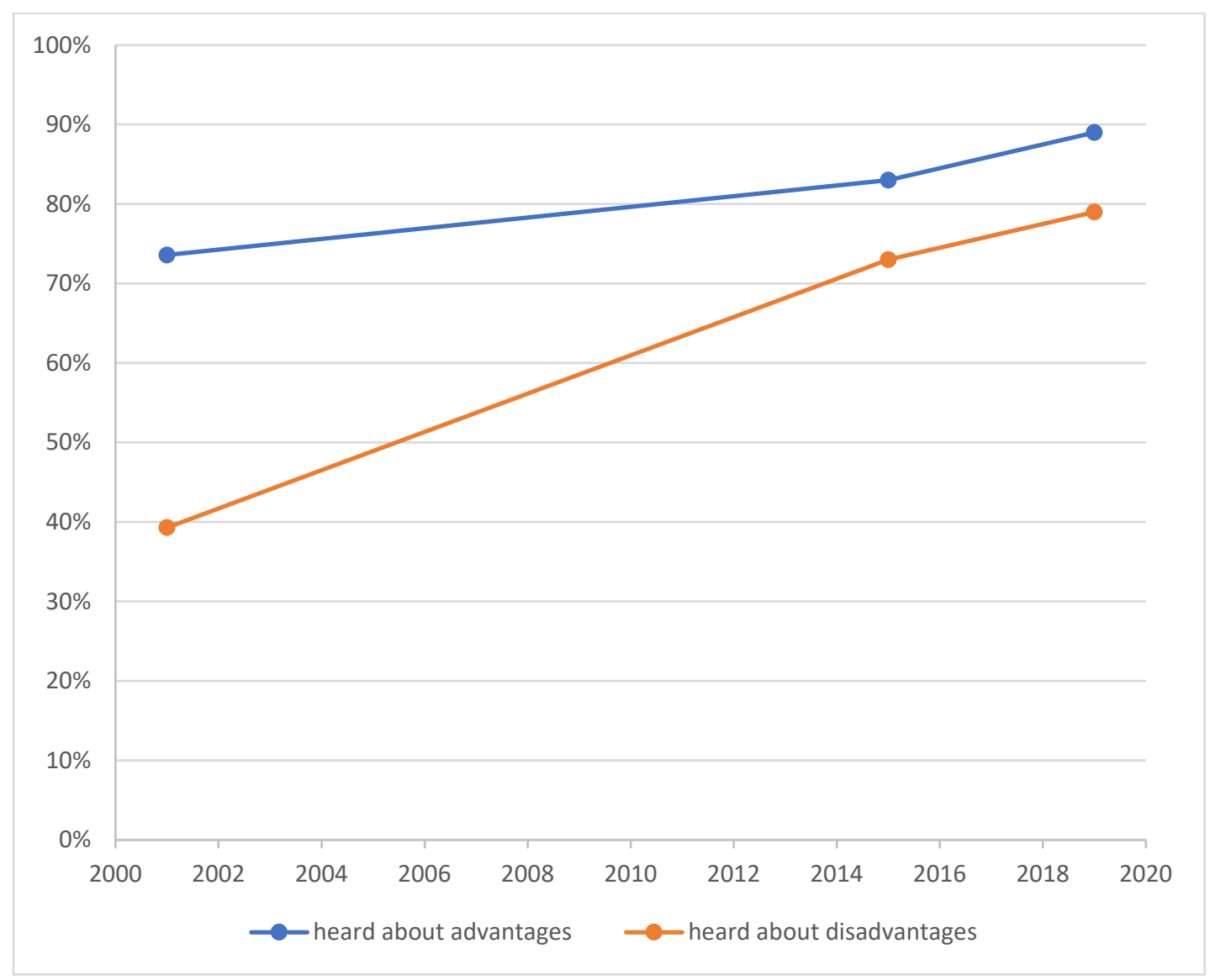

Figure 1. Information about childhood vaccines. "How much have you, personally, heard about the advantages [disadvantages] of vaccinations for children -- a great deal, fair amount, only a little, or nothing at all?" Figure shows percentage reporting "great deal" or "fair amount". For details, see Supplementary Material, tables 1.1, 1.2.

\section{Perceived Utility of Vaccines}

Figure 2 displays trends in perceived benefits of vaccines in general. Since at least 2008, there has been a notable decline in terms of both their perceived value to society and their value personally. 
Specifically, the percentage of Americans saying that vaccines are very important to the health of society dropped 9 points between November 2008 and January 2020. And, the percentage of Americans who strongly agree that they have personally benefitted from the development of vaccines fell 16 points from November 2008 to May 2018, and then fell another 10 points by August 2020. In the case of this latter drop, the emergence of COVID-19 vaccination as a national issue may be coloring vaccine opinions in general.

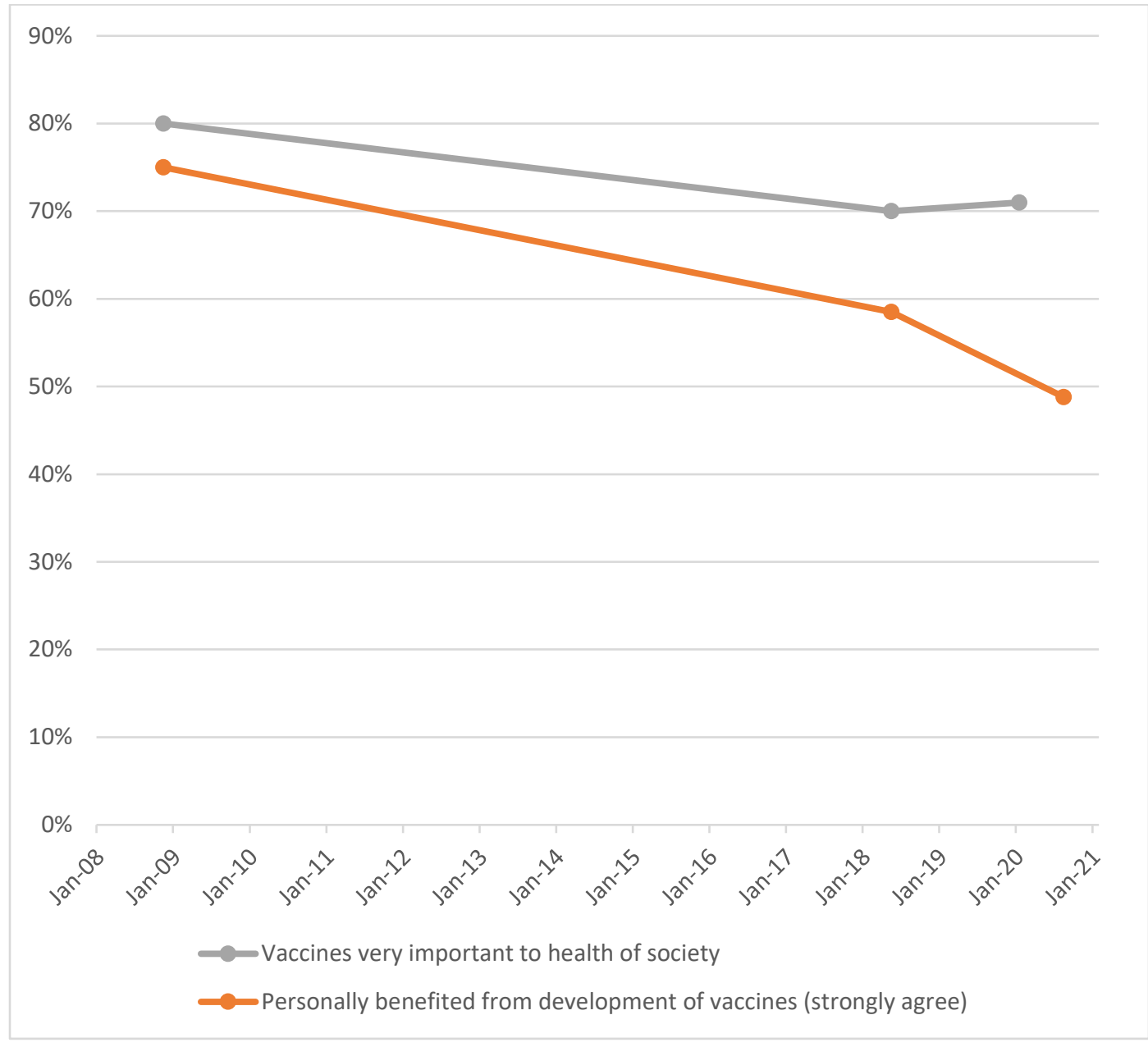

Figure 2. Perceived benefits of vaccines generally. "Thinking about the common vaccines available today such as polio, tetanus, measles, and flu, how important do you believe vaccines are to the health of our society today?" (Very, somewhat, not too, not at all); figure shows percent reporting "very important". "Do you believe that you have personally benefited from the development of vaccines over the last 50 years?" (Strongly yes, somewhat yes, somewhat no, strongly no); figure shows percent reporting "strongly yes". For details, see Supplementary Material, tables 2.1, 2.2. 
Another line of inquiry that taps into Americans' feelings about the utility of vaccines is the degree to which they believe that vaccinating children is important. Figure 3 shows that the percentage of Americans who believe it is "very" or "extremely" important to vaccinate children dropped 10 points between 2001 and 2015, then remained level through 2019. A separate series finds the percentage stating it is "very important" dropped 11 points between 2008 and 2018, with a slight additional drop of 2 points by January 2020 .

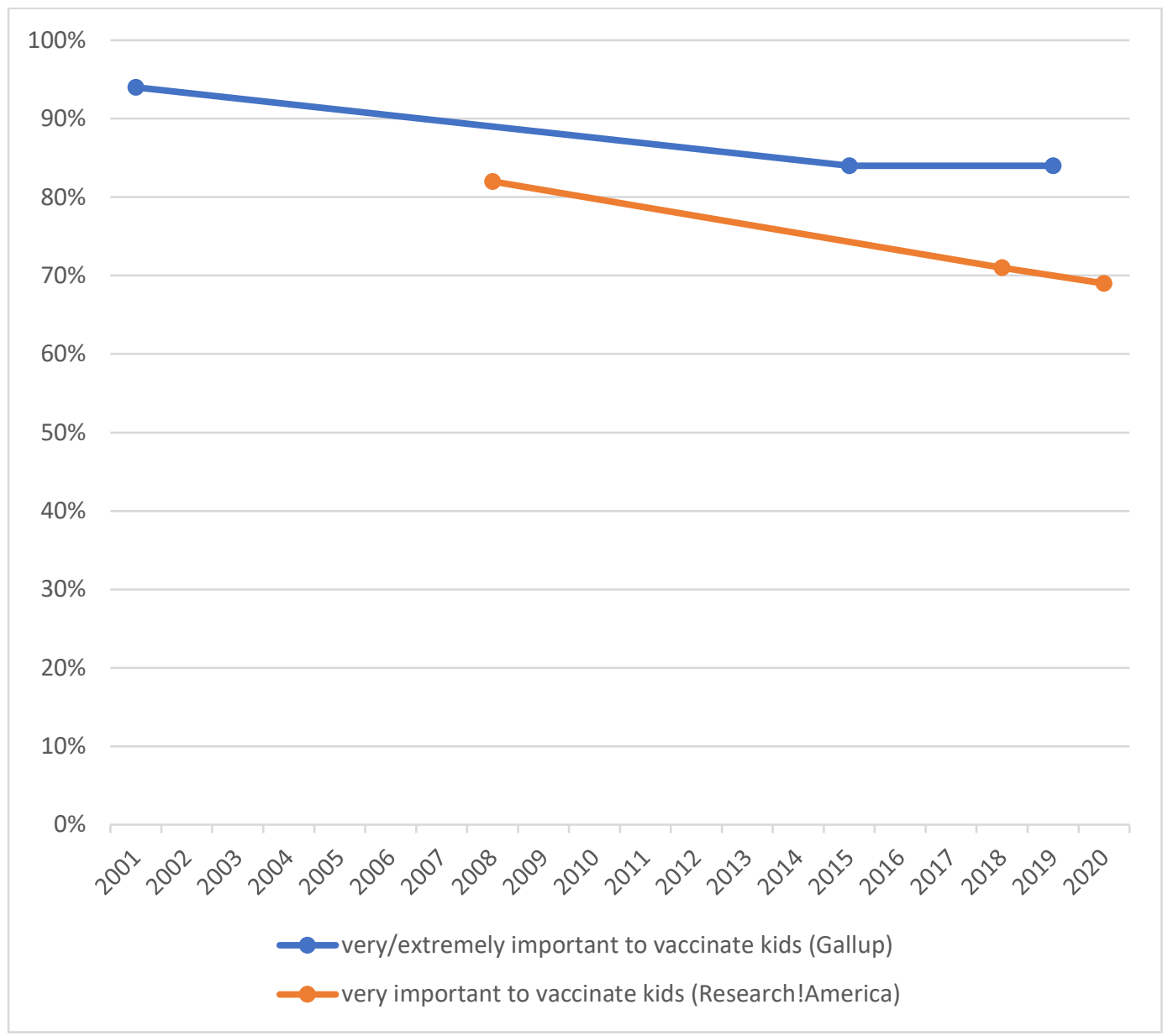

Figure 3. Perceived importance of parents vaccinating their children. Research!America: "How important do you believe it is for parents to have their children vaccinated?" (Very, somewhat, not too, not at all); figure shows percent reporting "very important". Gallup: "How important is it that parents get their children vaccinated-extremely important, very important, somewhat important, not very important, or not at all important?" Figure shows percent reporting "extremely"/"very important". For details, see Supplementary Material, tables 3.1, 3.2. 
A partisan breakdown for the Gallup series suggests a different trend among Democrats than among Republicans (figure 4). In 2001, Democrats were only 3 points more likely than Republicans to view vaccinating children as very important-not large enough to be statistically significant in a twotailed z-test. Through 2015, both parties' series experienced a somewhat similar decline, though the gap between them grew to 6 points - a modest but statistically significant difference. But over the next four years, the parties diverged even more starkly. Among Republicans, perceived importance of vaccinating children continued to decline, while among Democrats, it stopped its slide and instead increased. By 2019, the gap between the parties had grown to a significant and substantive 13-point difference-a much more partisan view of childhood vaccination.

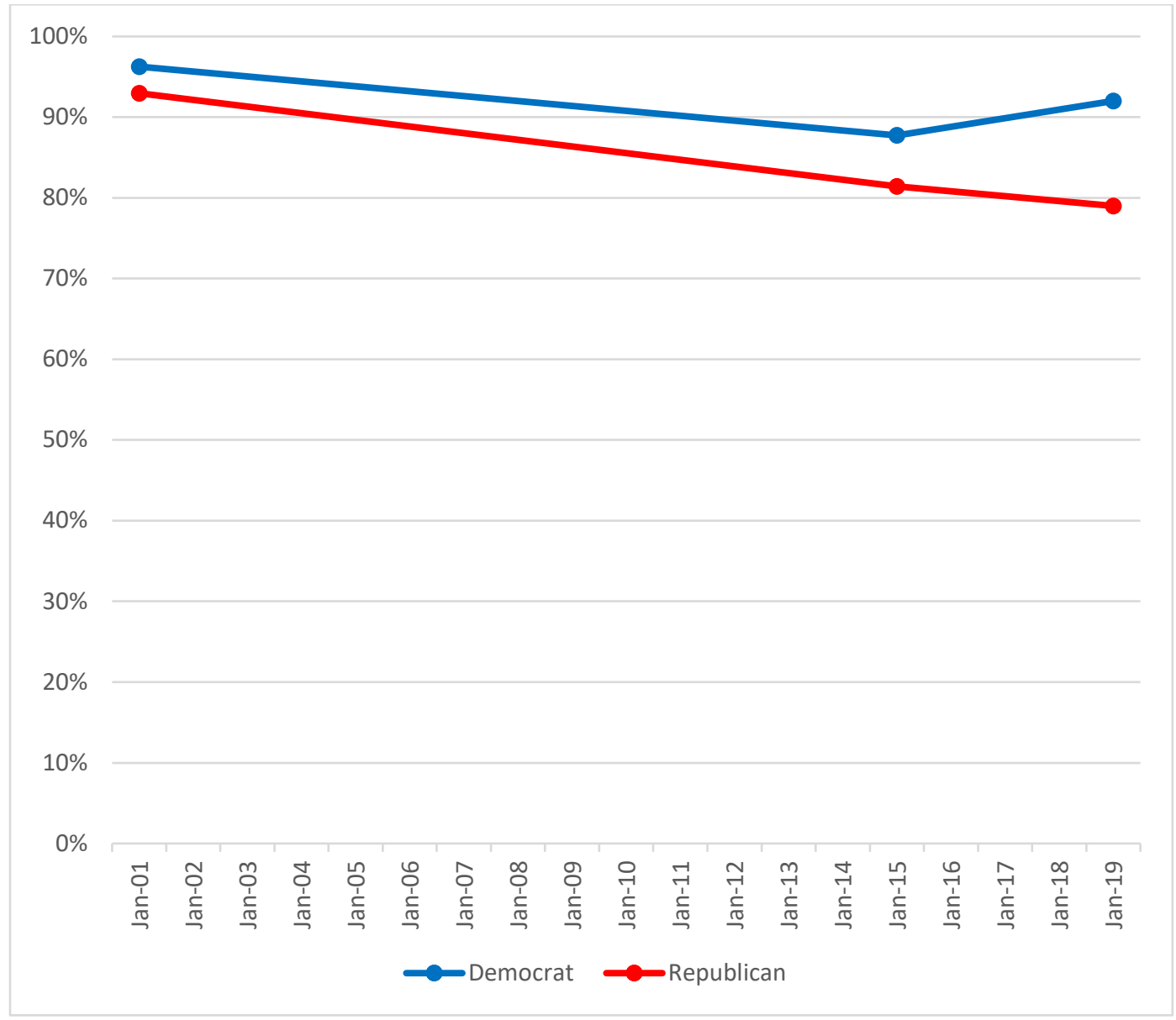

Figure 4. Perceived importance of parents vaccinating their children, by party. "How important is it that parents get their children vaccinated--extremely important, very important, somewhat 
important, not very important, or not at all important?" Figure shows percent reporting "extremely"/"very important". For details, see Supplementary Material, table 4.

\section{Perceived Safety of Vaccines}

The data also show a decline over the last two decades in Americans' perception that vaccines are safe. Figure 5 shows that the percentage of citizens saying they are very or somewhat confident in the safety of "vaccines used today" dropped 10 points from 2008 to 2018, was relatively stable through January 2020, then dropped 9 points over the next seven months-a time period during which the possibility of a new COVID-19 vaccine was highly salient. A different series suggests a more modest decline in perceived safety of vaccines-though this is likely due to the fact that it does not extend past 2019 and that its question is posed in more stark terms. Specifically, Gallup asked, "Do you think vaccines are more dangerous than the diseases they are designed to prevent, or not?" The percentage of Americans answering "no" dropped by a small but statistically significant 4 points between 2001 and 2019. 


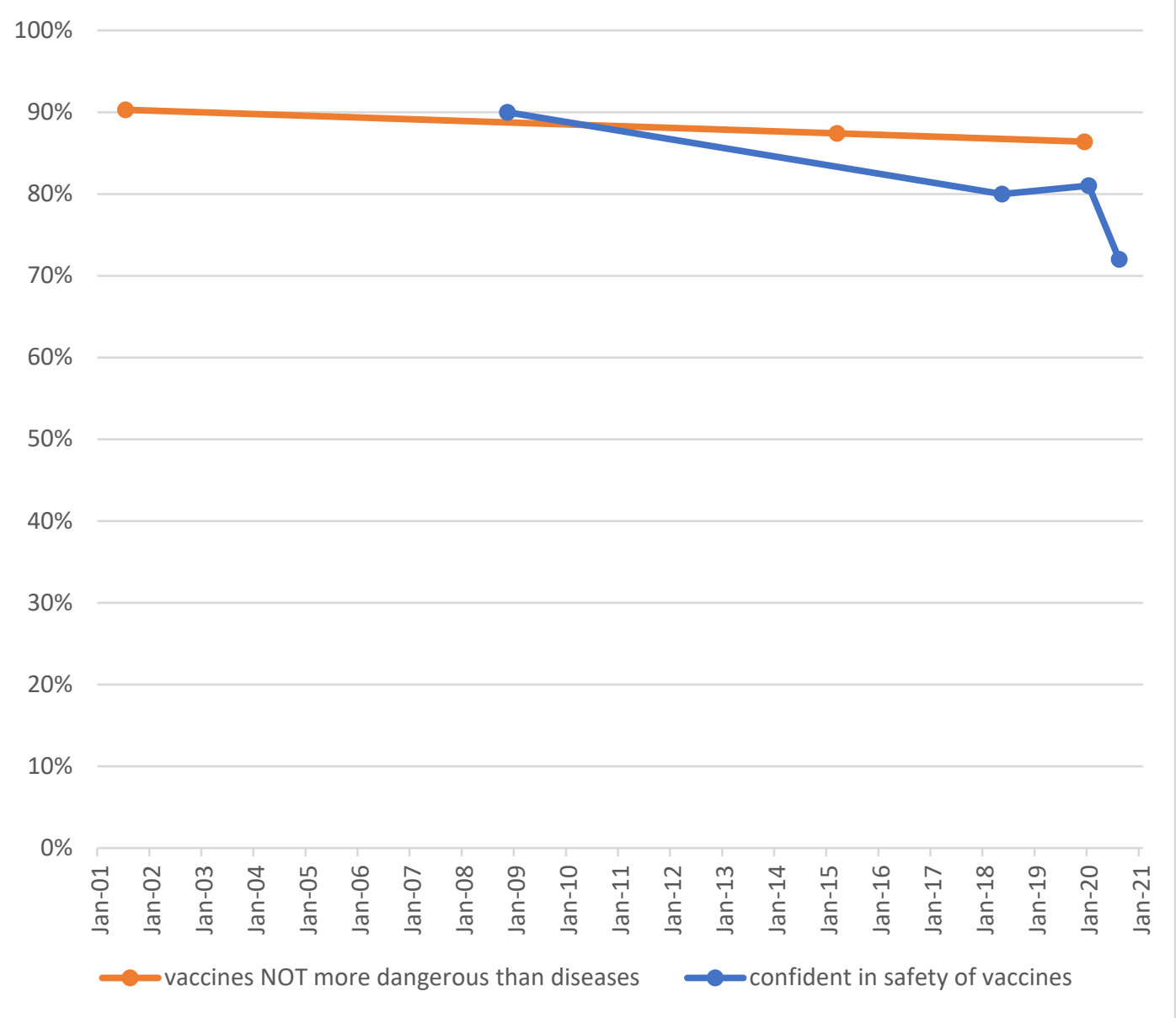

Figure 5. Perceived safety of vaccines generally. "In general, how confident are you in the safety of vaccines used today?" (very, somewhat, not too, not at all); figure shows percent reporting "very" or "somewhat". "Do you think vaccines are more dangerous than the diseases they are designed to prevent, or not?" (yes, no); figure shows percent reporting "no". For details, see Supplementary Material, tables 5.1, 5.2.

Turning to partisan groups, figure 6 shows a pattern similar to that found in figure 4 . Both parties hold similar, (slightly) declining views on vaccine safety from 2001 through 2015. But by 2019, a clear partisan gap emerges. Democratic perceptions of vaccine safety rebound slightly, while Republican perceptions drop 5 more points, opening up a statistically significant 6-point partisan split. 


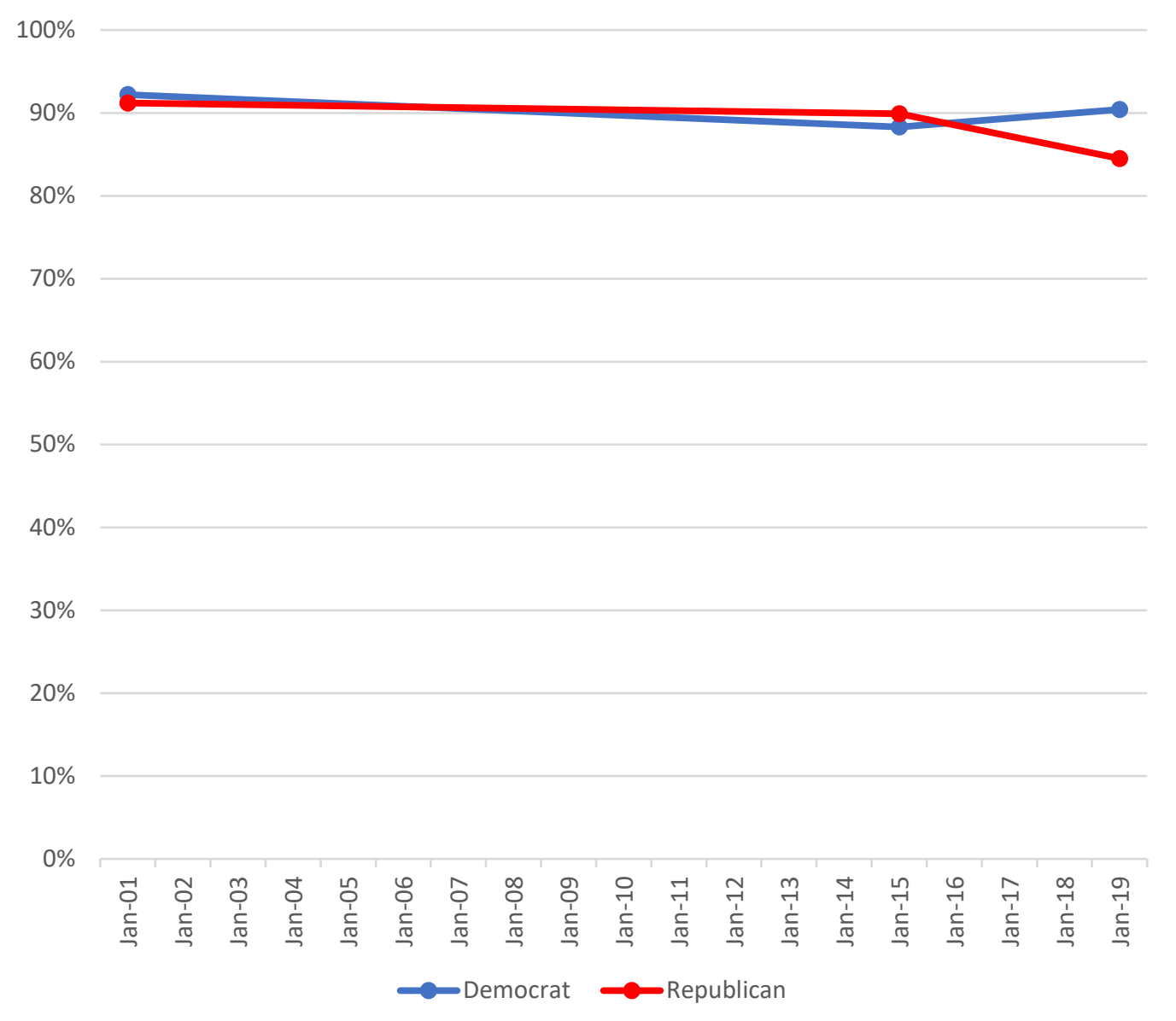

Figure 6. Perceived safety of vaccines generally, by party. "Do you think vaccines are more dangerous than the diseases they are designed to prevent, or not?" Figure shows percent reporting "no". For details, see Supplementary Material, table 6.

Regarding the safety of childhood vaccines specifically, figure 7 shows the percentage of Americans who feel vaccines given to children are "very safe" declined 14 points from February 2015 to May 2020. After that, perceptions of vaccine safety begin to trend in the opposite direction, increasing 9 points by October 2021. Of course, extending the series into 2021 means that many Americans would have contemporaneously been thinking about COVID vaccination, and their attitudes on this issue may have influenced their attitudes regarding vaccine safety in general. 


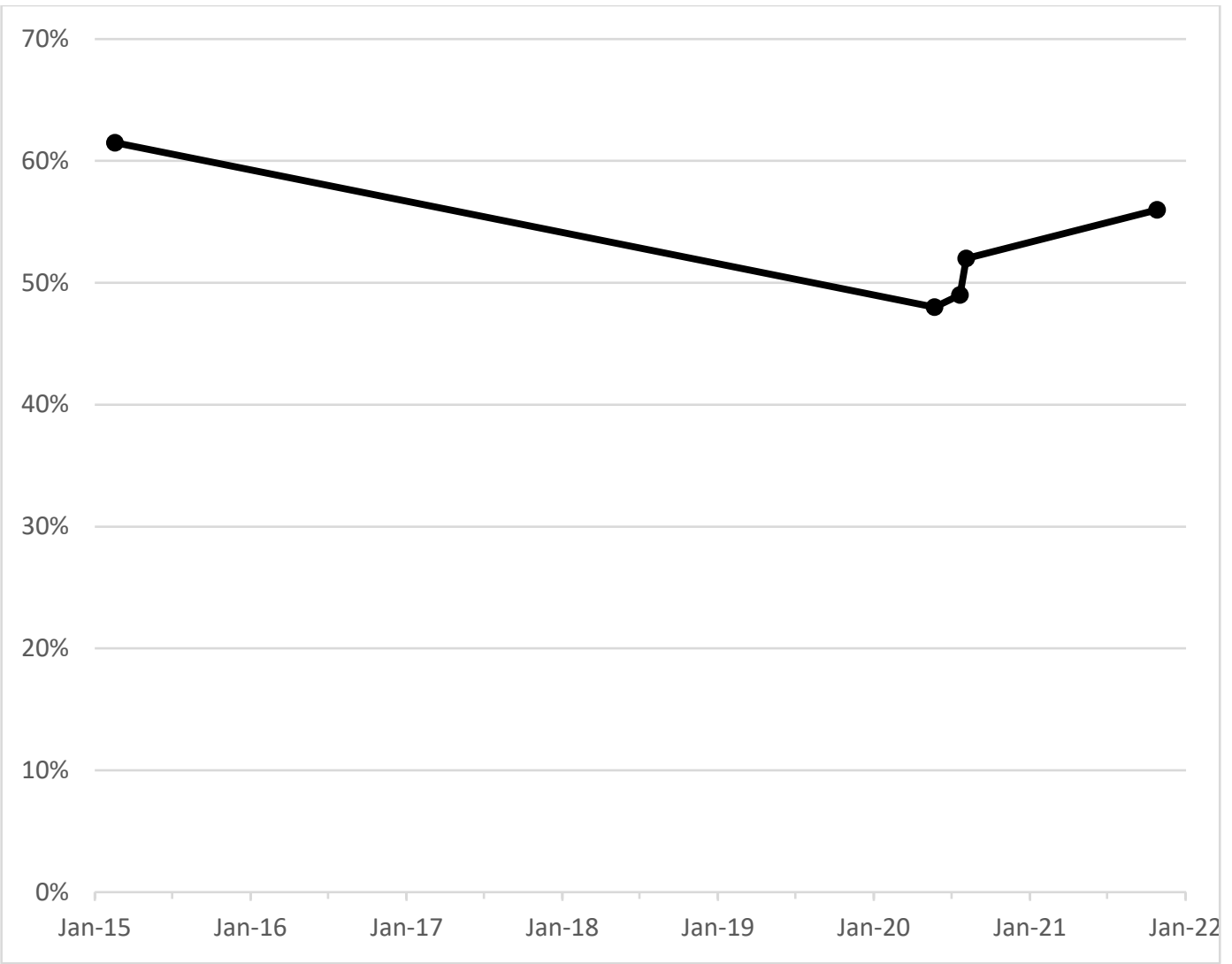

Figure 7. Perceived safety of childhood vaccines. "In general, how safe are vaccines given to children for diseases like measles, mumps, and rubella-very safe, somewhat safe, not very safe, or not safe at all?" Figure shows percent reporting "very". For details, see Supplementary Material, table 7.

Looking at the same question broken down by party, figure 8 shows that the late, upward trend from figure 7 seems to be driven by a corresponding increase among Democratic partisans specifically, with no upward trend among Republicans. In terms of the gap between the parties, similar to figure 4 we see an 8-point difference in 2015 , a difference that holds relatively steady over the next four to five years. Then, from late 2020 through 2021, the partisan gap in perceived safety of childhood vaccines balloons to a 26-point difference. Again, the very public and partisan battles about COVID vaccines during this period may be an indirect cause of this late partisan split. 


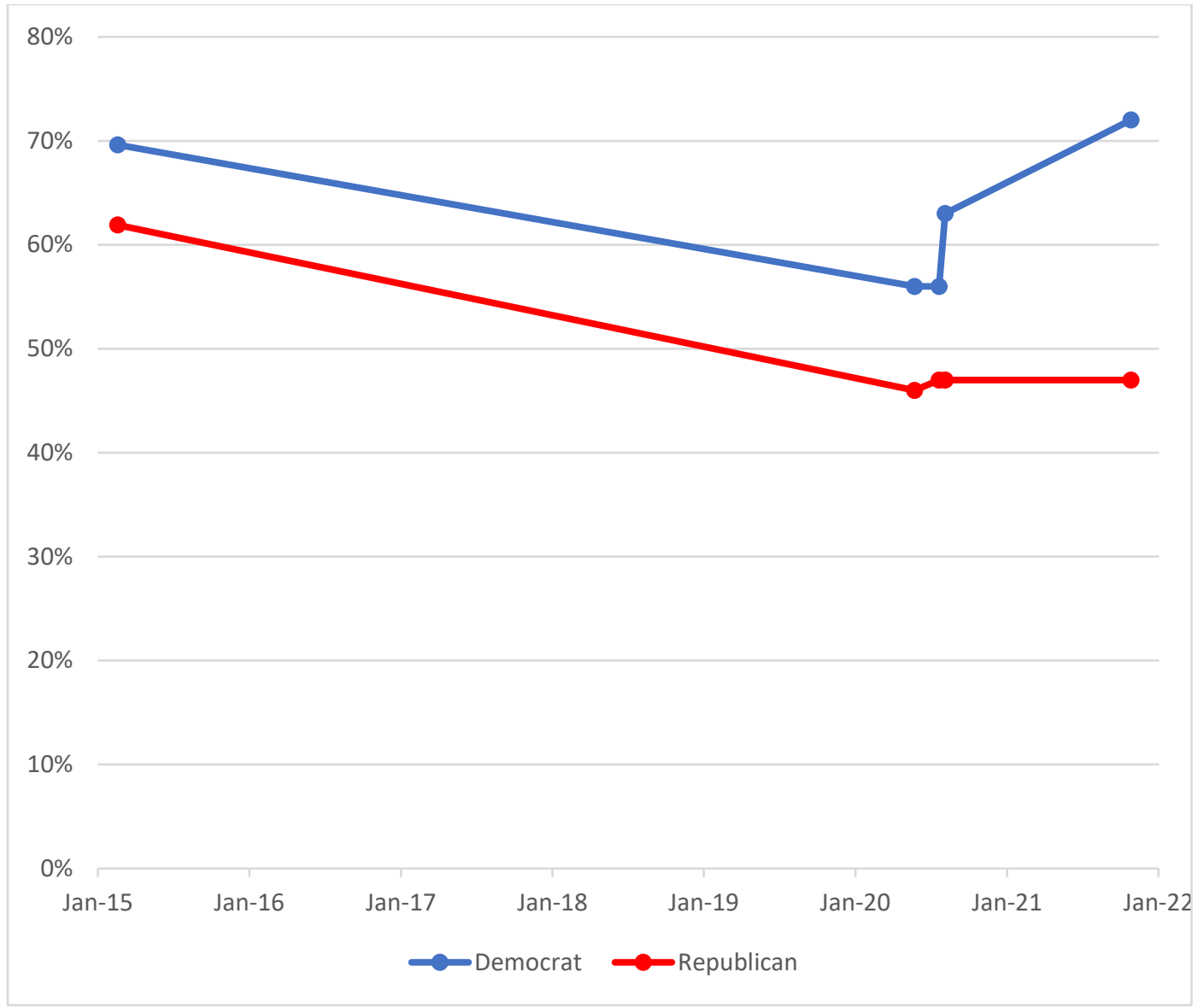

Figure 8. Perceived safety of childhood vaccines, by party. "In general, how safe are vaccines given to children for diseases like measles, mumps, and rubella-very safe, somewhat safe, not very safe, or not safe at all?" Figure shows percent reporting "very". For details, see Supplementary Material, table 8.

\section{Support for Vaccination Requirements}

Based on a few closely related measures, it appears that public support for childhood vaccination requirements (which have existed in every US state since 1980) fell by approximately 20 points points between 1991 and 2021 (figure 9). 


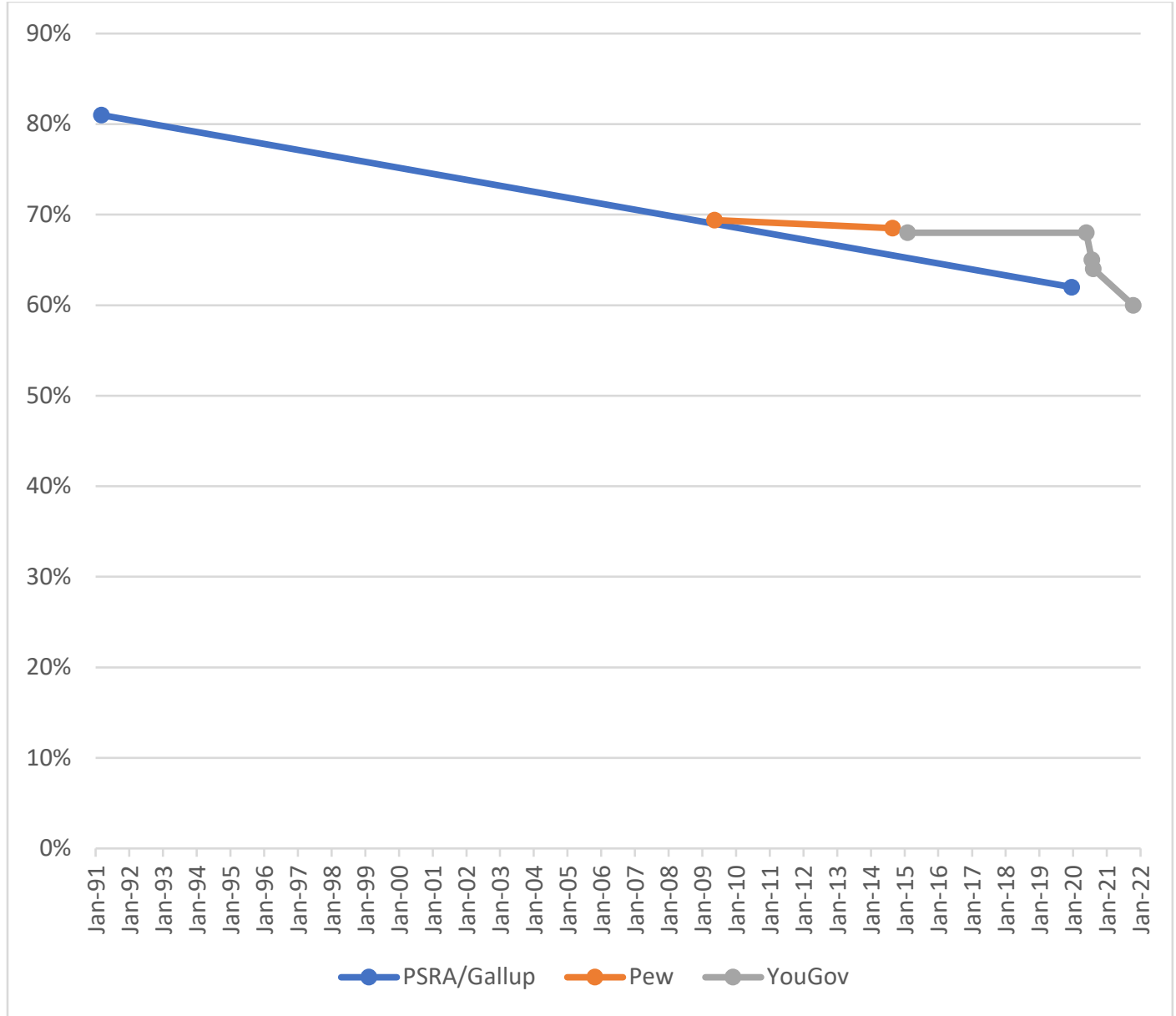

Figure 9. Support for requiring childhood vaccinations. PSRA/Gallup: "Do you think the government should require all parents to have their children vaccinated against contagious diseases such as measles, or do you think that's something the government should stay out of?" Pew: "Thinking about childhood diseases, such as measles, mumps, rubella and polio...should parents be able to decide not to vaccinate their children or should all children be required to be vaccinated?" YouGov: "Do you think [the government should or should not require parents/parents should be required to] have their children vaccinated against infectious diseases?" For details, see Supplementary Material, tables 9.1-9.3.

Party breakdowns are available for the two most recent series (figure 10). Since 2009,

Republicans have followed the same downward trajectory as for the overall trend, albeit with a steeper decline. Democrats display the opposite pattern. Pew data show a 5-point increase in Democratic support for childhood vaccination requirements from 2009 to 2014. Then, according to YouGov data, after a steady period over the next five years, there is another 6-point increase in Democratic support from August 2020 to October 2021. These divergent patterns for each party lead to a corresponding 
expansion in the gap between the them on this issue. In 2009, there was no partisan difference. By the middle of the next decade, a divergence of 12 to 14 points emerged. By 2021, this gap had grown dramatically, to nearly 40 points.

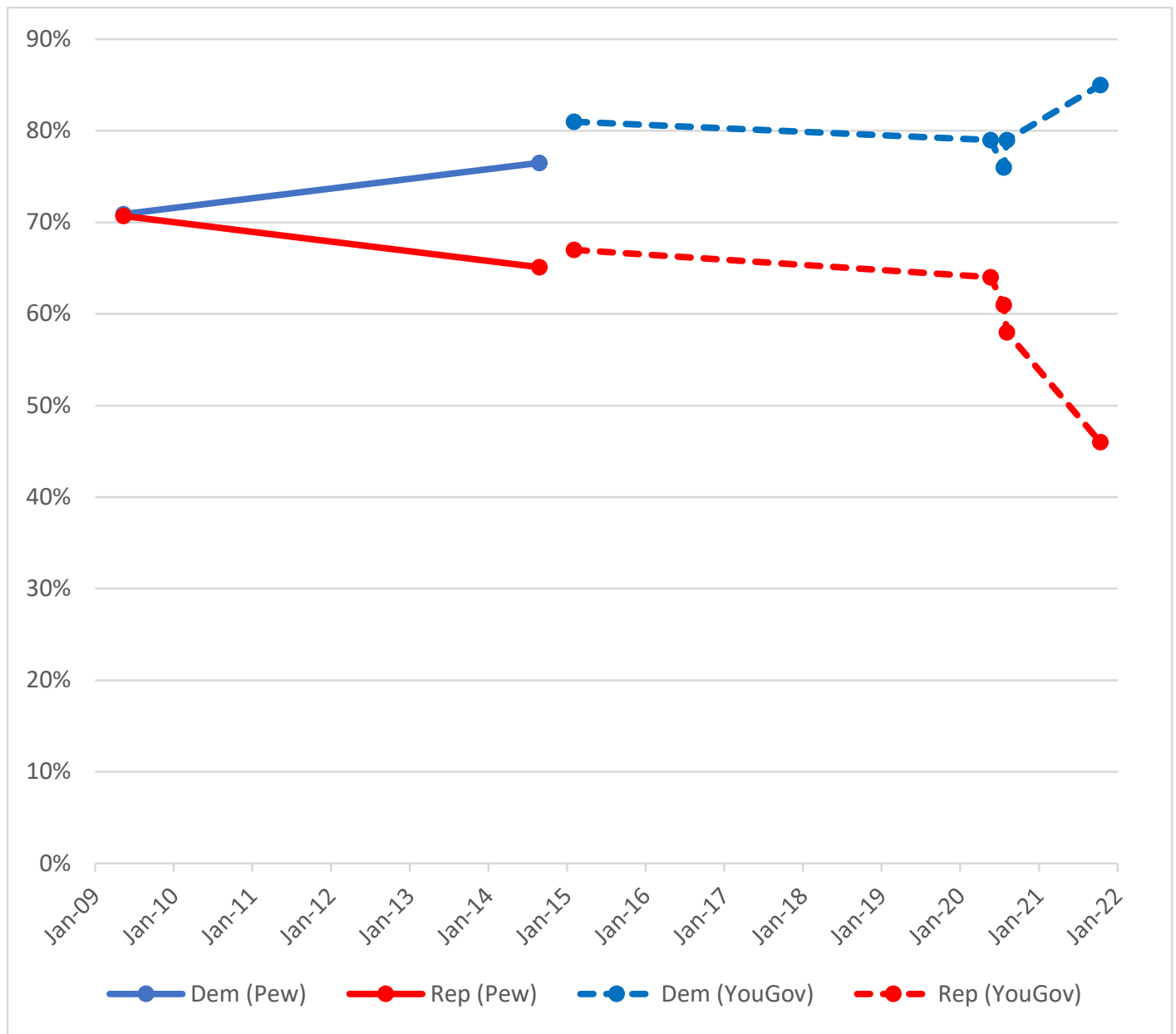

Figure 10. Support for requiring childhood vaccinations, by party. Pew: "Thinking about childhood diseases, such as measles, mumps, rubella and polio...should parents be able to decide not to vaccinate their children or should all children be required to be vaccinated?" YouGov: "Do you think [the government should or should not require parents/parents should be required to] have their children vaccinated against infectious diseases?" For details, see Supplementary Material, tables 10.1, 10.2. 


\section{Willingness to vaccinate}

This section looks at Americans' vaccination willingness for a few different types of diseases: childhood diseases such as measles, mumps, and rubella (MMR), the seasonal flu, and discrete "crisis" diseases from the past seventy years.

$M M R$ Vaccine

Figure 11 displays the National Immunization Survey's (NIH) estimated percentage of MMR vaccination among the population expected to have received it each year from 1994 to 2017 (the most recent year available). The figure has fairly consistently hovered within a point or two of its 91 percent average, with no discernable trend. It is notable that we find no downward trend comparable to that found in figure 4 or 7 -both of which dealt specifically with childhood vaccine attitudes. However, this dissimilarity between attitudes and behavior can be readily explained by the longstanding existence of childhood vaccination requirements in all 50 states.

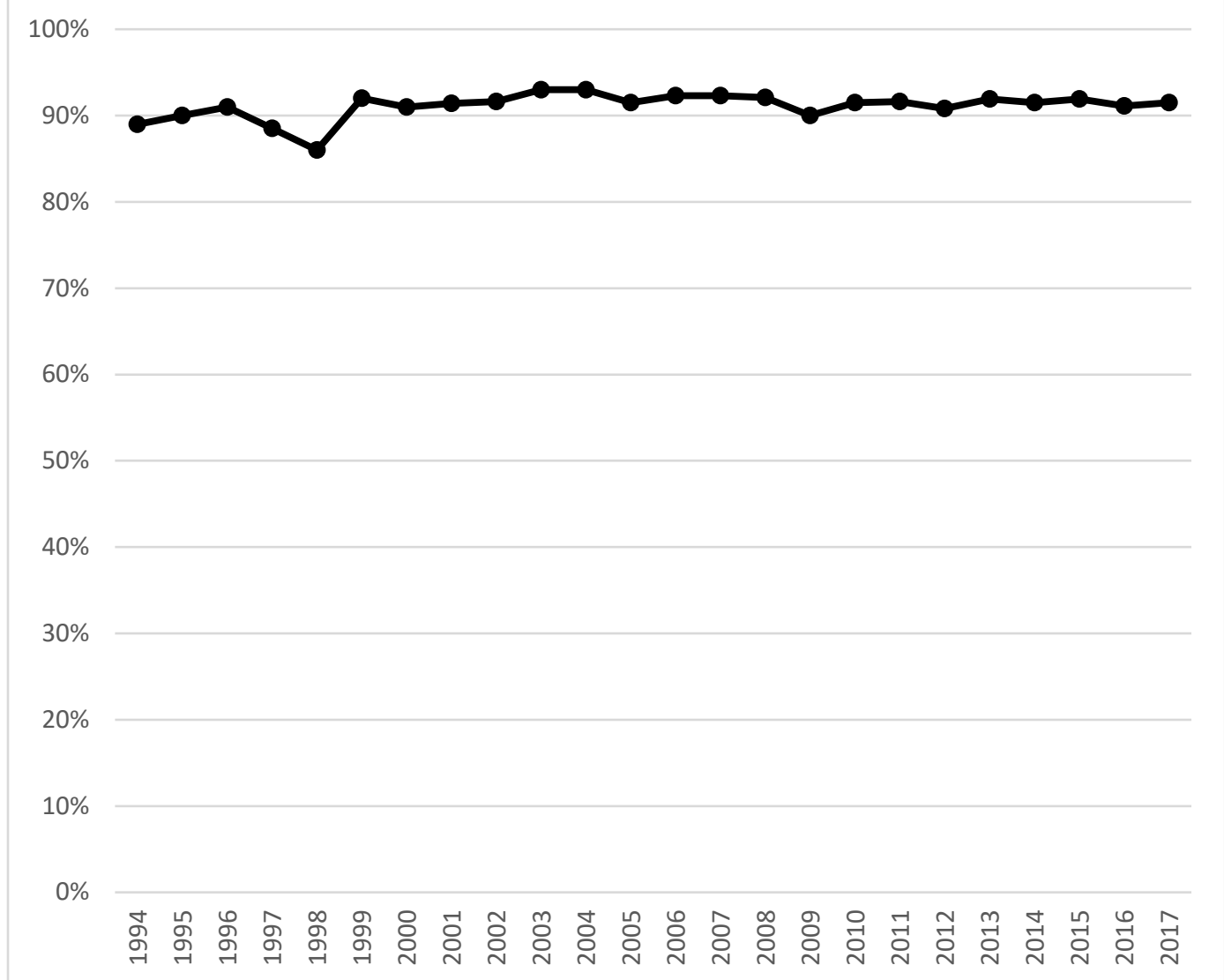


Figure 11. MMR vaccination among 19-35 months-old children. Data from National Immunization Survey-Child. For details, see Supplementary Material, table 11.1.

NIS data do not permit a breakdown by party. However, comparing two similar (but not identical) questions from other organizations suggests that partisans' willingness to vaccinate children for childhood diseases such as MMR may have polarized in recent years. In a 2015 CBS poll there is no statistically significant difference in reported childhood vaccination rates between Democratic and Republican parents. But in two Kaiser polls from 2021 the vaccination rate for childhood diseases such as MMR is significantly higher for Democrats than for Republicans (for details, see Supplementary Material, tables 11.2, 11.3).

Seasonal Flu Vaccine

According to the National Health Interview Survey (NHIS), the percentage of adults who report getting a flu vaccination in the past twelve months has steadily increased from 21 percent in 2005 to 48 percent in 2020 (figure 12). A highly similar pattern is found in a series of sporadic YouGov polls. This pattern of increasing flu vaccination behavior contrasts not only with the steady, high level of childhood vaccination behavior but also with the negative trend in general vaccine attitudes from tables 2 and 5 . Again, these differences may be at least partly explained by policy context. Specifically, there are no state requirements for flu vaccination, so baseline flu vaccination behavior has been relatively low. In 2010, the CDC for the first time formally recommended every American get a seasonal flu vaccination each year. Given the low baseline, this recommendation appears to have gradually prompted more and more Americans to view flu vaccination as a regular habit. One would not expect the CDC recommendation to eventually persuade die-hard vaccine skeptics, however. 


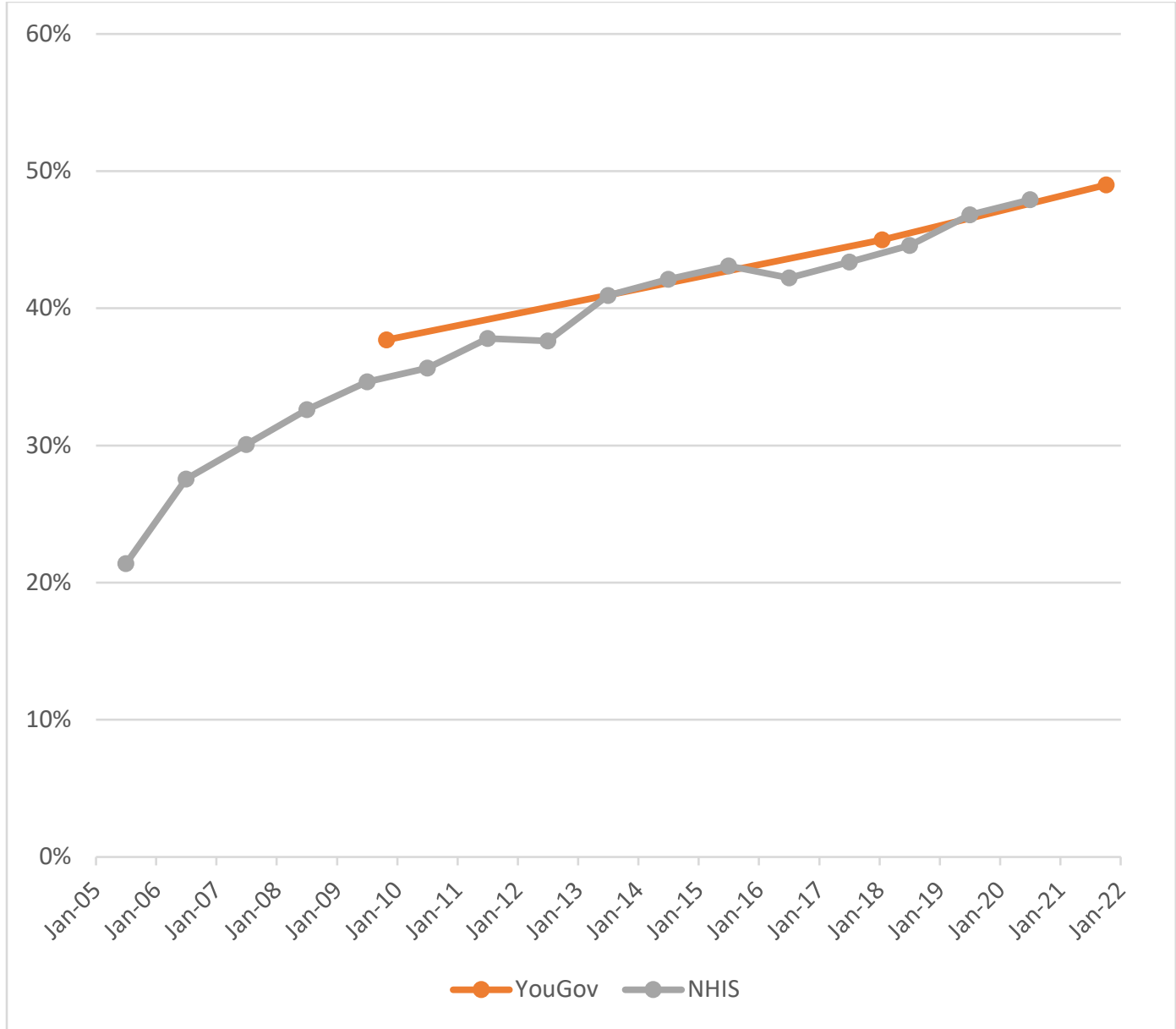

Figure 12. Seasonal flu vaccination among adults. NHIS: "During the past 12 months, have you had a flu vaccination? A flu vaccination is usually given in the fall and protects against influenza for the flu season." YouGov: "Last year, did you get a flu shot? (2009) / Have you gotten a flu shot this season? (2018) / Did you get the influenza vaccine (flu shot) last year in 2020? (2021). For details, see Supplementary Material, tables 12.1, 12.2.

Breaking the flu data out by party, a familiar pattern appears (figure 13). Specifically, responses in the early part of the series (2009) show no significant difference between Democrats and Republicans in terms of their reported flu vaccination rates. By 2018, a small but statistically significant difference of 5 percentage points emerges. In 2021, the gap between Democrats and Republicans balloons to 14 points. 


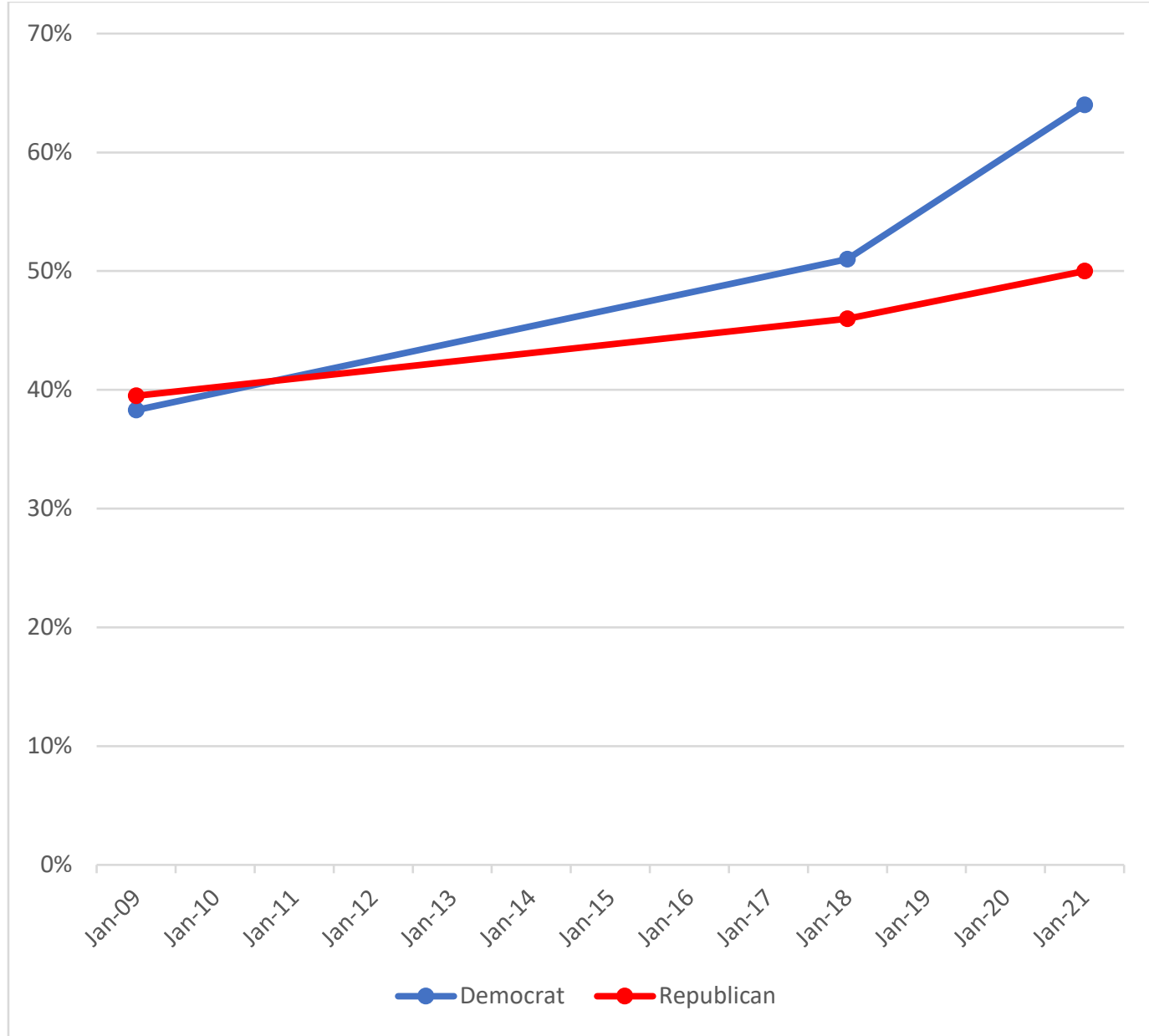

Figure 13. Seasonal flu vaccination among adults, by party. "Last year, did you get a flu shot? (2009) / Have you gotten a flu shot this season? (2018) / Did you get the influenza vaccine (flu shot) last year in 2020? (2021). For details, see Supplementary Material, tables 13.1, 13.2.

\section{New "Crisis" Vaccines}

There are a few time periods over the last 70 years during which Americans faced a health crisis for which the potential remedy was a new (or newly reintroduced) vaccine. The context surrounding each new crisis vaccine is largely unique. For example, there may be differences in anticipated effectiveness, side effects, perceived danger from the disease, and current political leadership. For all these reasons, public opinion data on different crisis vaccines cannot be viewed as directly comparable to one another. At the same time, the very fact that there are so many potential differences across crisis vaccines makes it interesting to check to see if-despite these differences-there are any clear patterns in public reactions to them. 
Survey data on Americans' willingness to take a new (yet to be released) vaccine designed to alleviate a current health crisis or concern exists for six vaccines: polio (1954), Asian flu (1957), swine flu (1976), smallpox (2002), swine flu (2009), and COVID-19 (2020). For each vaccine, figure 14 uses the earliest available data point, reporting the percentage of adults who said they would get the vaccine if it were available. Despite the myriad differences in each particular context, there is a surprising degree of commonality in initial willingness to get each vaccine. Across these six, a majority is willing in every case, and the range of willingness is in a relatively narrow band, from a low of 54 percent (swine flu '76) to a high of 66 percent COVID).

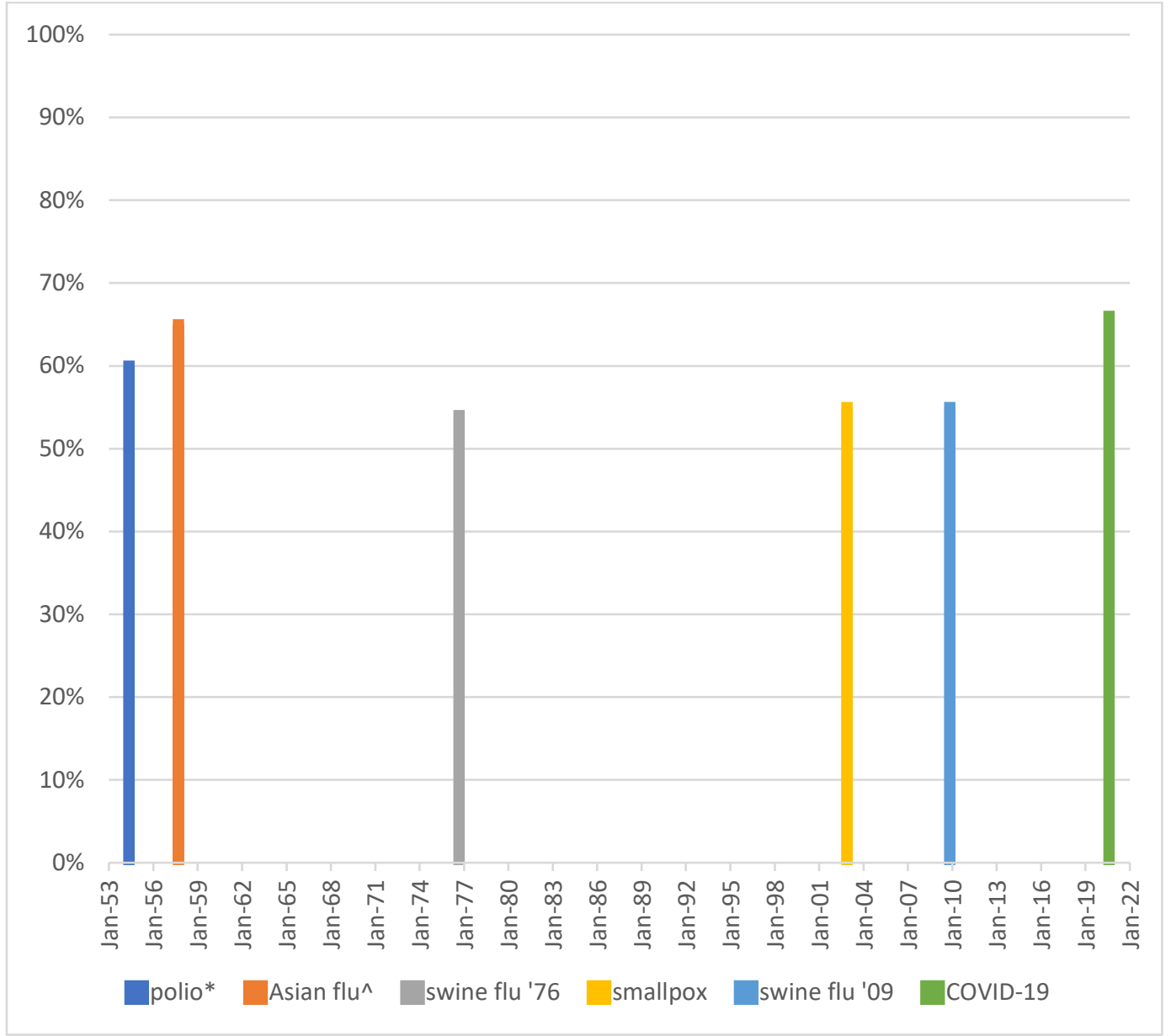

Figure 14. Willingness to take new vaccines. Polio: "Would you like to take this new polio vaccine (to keep people from getting polio) yourself?" (Gallup; *asked only of the $90 \%$ who had heard/read about the vaccine). Asian Flu: "If a vaccine becomes available, do you plan to take shots to protect against this [Asian] flu, or not?" (Gallup; ^asked only of the 92\% who had 
heard/read about the vaccine). Swine flu '76: "Do you think you personally will get an inoculation against swine flu this fall or not?" (Roper). Smallpox: "Would you, personally, get a smallpox vaccine if it were available?" (Gallup). Swine flu '09: "Suppose a vaccine for the swine flu virus is developed later this year (2009). Do you think you, personally, would or would not get this vaccine?" (Gallup). COVID-19: "If an FDA-approved vaccine to prevent coronavirus/COVID-19 was available right now at no cost, would you agree to be vaccinated?" (Gallup). For details, see Supplementary Material, tables 14.1-14.6.

While the overall rates are similar across the vaccines, party differences for each vaccine differ substantially. To aid in comparing across vaccines, figure 15 uses each vaccine's overall rate of willingness as a baseline, and then displays the degree to which each party diverged from that vaccinespecific overall rate. For example, for the polio vaccine in 1954, Democrats were 1 point more willing and Republicans 1 point less willing to take the vaccine than the 60 percent average in the general population-a 2-point partisan gap. In the twentieth century, none of the three new vaccines displayed a double-digit partisan gap. But since 2000, all three of the new (or newly reintroduced) vaccines display double-digit partisan gaps, with the largest gap belonging to the most recent vaccine for COVID-19-37 points. 


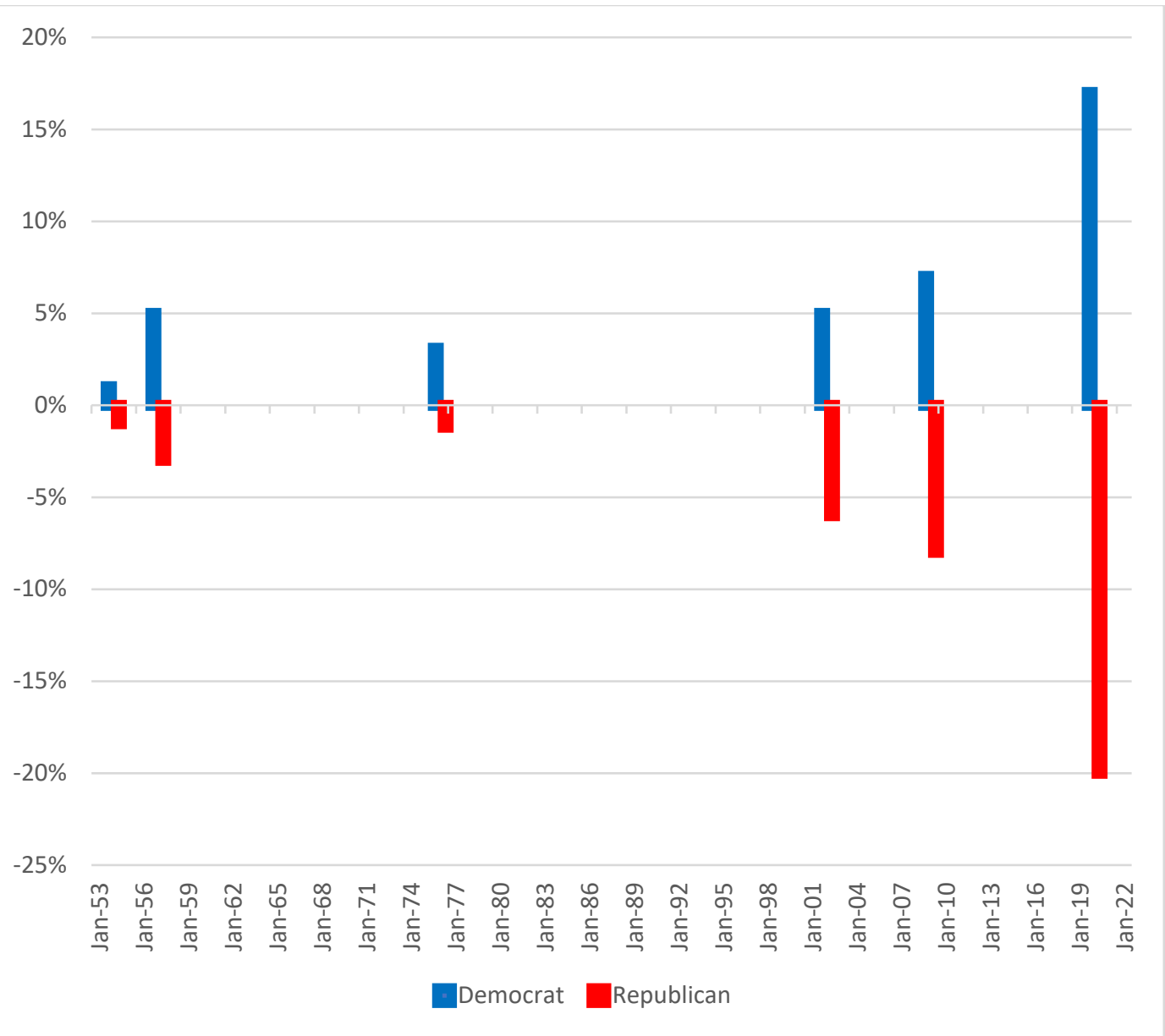

Figure 15. Party differences in willingness to take new vaccines. Polio '54: "Would you like to take this new polio vaccine (to keep people from getting polio) yourself?" (Gallup; *asked only of the 90\% who had heard/read about the vaccine). Asian Flu '57: "If a vaccine becomes available, do you plan to take shots to protect against this [Asian] flu, or not?" (Gallup; "asked only of the 92\% who had heard/read about the vaccine). Swine flu '76: "Do you think you personally will get an inoculation against swine flu this fall or not?" (Roper). Smallpox '02: "Would you, personally, get a smallpox vaccine if it were available?" (Gallup). Swine flu '09: "Suppose a vaccine for the swine flu virus is developed later this year (2009). Do you think you, personally, would or would not get this vaccine?" (Gallup). COVID-19, 2020: "If an FDA-approved vaccine to prevent coronavirus/COVID-19 was available right now at no cost, would you agree to be vaccinated?" (Gallup). Figure displays the percentage point difference from each vaccine's overall rate. For details, see Supplementary Material, tables 14.1-14.6.

\section{Summary}

Looking over all the data presented here, four key patterns emerge. First, Americans are hearing more information about vaccines in recent years than they did at the beginning of the twenty-first 
century - at least regarding childhood vaccines - and the biggest increase has occurred for negative information.

Second, supportive attitudes regarding vaccines' utility, safety and appropriateness of requirements have all fallen since the 1990s and early 2000s, with a clear decline somewhere between 2008 and 2015. Another steep drop in supportive attitudes has occurred since early 2020-coinciding with the COVID-19 pandemic.

Third, policy context appears to make a big difference in reported vaccination behavior across vaccine types. For example, the relatively high rate at which parents vaccinate their children for MMR in the face of declining favorable attitudes towards such vaccines suggests that government mandates can be effective in boosting vaccination higher than preferences alone would suggest. Also, increasing rates of seasonal flu vaccination over the last decade suggest that CDC recommendations can sometimes boost vaccine uptake among those who are not unalterably opposed to it-although not necessarily among the vaccine skeptical.

Finally, the partisan breakdowns in this study suggest that vaccine skepticism was largely apolitical prior to at least 2009. By 2015, a partisan spit emerged across not only vaccine attitudes, but also in reported vaccination behavior. It seems particularly noteworthy that a partisan split emerged on the seemingly innocuous subject of seasonal flu vaccination, and that this split pre-dates the polarization clearly observed in the COVID-19 era. This finding helps to further emphasize that politicization of vaccines is not limited to those specific vaccines being discussed by politicians in the news media at a given point in time. Rather, the politicization of vaccines runs deep enough to permeate across multiple subtopics and endure across various political and informational environments. 


\section{References}

Hussain A, Ali S, Ahmed M, Hussain S. 2018. "The Anti-vaccination Movement: A Regression in Modern Medicine." Cureus 10(7): e2919.

Krause, Nicole M., Dominique Brossard, Dietram A. Scheufele, Michael A. Xenos, and Keith Franke. 2019.

"Trends-Americans' Trust in Science and Scientists." Public Opinion Quarterly 83(4): 817-836.

Zaller, John R. 1992. The Nature and Origins of Mass Opinion. Cambridge University Press. 


\section{Online Supplementary Material}

\section{Table of Contents}

Survey Methods p. 1

Supplementary Tables $\quad$ p. 6

\section{Survey Methods}

In this section, surveys are listed alphabetically by the survey organization (or sponsor) name that is referenced in the supplementary tables, and then chronologically by the reference date (last date of polling) listed in the tables. Information that could be linked is not listed in full. Any relevant information about methods that is not included here (text or link) was not publicly available. The source for almost all survey information and cross-tabulations is the Roper Center for Public Opinion Research's iPoll database. Where Roper is not the source, the source is noted in parentheses at the end of an entry.

CBS, 2/17/2015: This poll was conducted by telephone February 13-17, 2015 among 1,006 adults nationwide. Data collection was conducted on behalf of CBS News by SSRS of Media, PA. Phone numbers were dialed from samples of both standard land-line and cell phones. The error due to sampling for results based on the entire sample could be plus or minus three percentage points. The error for subgroups may be higher. Interviews were conducted in English and Spanish. This poll release conforms to the Standards of Disclosure of the National Council on Public Polls.

Gallup, 5/7/1954: Study Date: May 2, 1954 - May 7, 1954; Geographic Coverage: United States; Sample: National Adult; Sample Size: 1415; Interview Method: Face-to-face interview

Gallup, 9/4/1957: Study Date: August 29, 1957 - September 4, 1957; Sample: National Adult; Sample Size: 1528; Geographic Coverage: United States; Interview Method: Face-to-face interview.

Gallup, 3/1/2001: Results for this Gallup poll are based on telephone interviews conducted Feb. 28-March 1, 2015, on the Gallup U.S. Daily survey, with a random sample of 1,015 adults, aged 18 and older, living in all 50 U.S. states and the District of Columbia. For results based on the total sample of national adults, the margin of sampling error is \pm 4 percentage points at the $95 \%$ confidence level. All reported margins of sampling error include computed design effects for weighting. Each sample of national adults includes a minimum quota of 50\% cellphone respondents and 50\% landline respondents, with additional minimum quotas by time zone within region. Landline and cellular telephone numbers are selected using random-digit-dial methods.

Gallup, 7/1/2001: Conducted June 28, 2001 - July 1, 2001; National adults; Sample Size: 1014; Geographic Coverage: United States; Interview Method: Telephone interview; Weighted. 
Gallup, 11/14/2002: Study Date: November 11, 2002 - November 14, 2002; Sample: National adult; Sample Size: 1001; Geographic Coverage: United States; Interview Method: Telephone interview.

Gallup, 5/5/2009: Sponsor: USA Today Field Dates: May 5, 2009 Sample: National adult Sample Size: 1,014 Sample Notes: This study contains sampling using landline telephones and cellular phones.

Gallup, 12/5/2019: Results are based on telephone interviews conducted December 2-15, 2019 with a random sample of $-1,025$-adults, ages $18+$, living in all 50 U.S. states and the District of Columbia. For results based on this sample of national adults, the margin of sampling error is \pm 4 percentage points at the $95 \%$ confidence level. For results based on the sample of -489 - national adults in Form A, the margins of sampling error is \pm 5 percentage points. For results based on the sample of -536-national adults in Form B, the margins of sampling error is \pm 5 percentage points. Interviews are conducted with respondents on landline telephones and cellular phones, with interviews conducted in Spanish for respondents who are primarily Spanish-speaking. Each sample of national adults includes a minimum quota of $70 \%$ cell phone respondents and $30 \%$ landline respondents, with additional minimum quotas by time zone within region. Landline and cell phone telephone numbers are selected using random digit dial methods. Gallup obtained sample for this study from Dynata. Landline respondents are chosen at random within each household on the basis of which member has the next birthday. Samples are weighted to correct for unequal selection probability, non-response, and double coverage of landline and cell users in the two sampling frames. They are also weighted to match the national demographics of gender, age, race, Hispanic ethnicity, education, region, population density, and phone status (cell phone-only/landline only/both and cell phone mostly). Demographic weighting targets are based on the March 2018 Current Population Survey figures for the aged 18 and older U.S. population. Phone status targets are based on the January-June 2018 National Health Interview Survey. Population density targets are based on the 2010 census. All reported margins of sampling error include the computed design effects for weighting. In addition to sampling error, question wording and practical difficulties in conducting surveys can introduce error or bias into the findings of public opinion polls. For questions about how this survey was conducted, please contact galluphelp@gallup.com.

Gallup, 7/26/2020: https://www.gallup.com/174158/gallup-panel-methodology.aspx (Source: topline on Gallup website; crosstabs requested from Gallup by authors)

KFF, 8/2/2021: https://www.kff.org/report-section/kff-covid-19-vaccine-monitor-parents-andthe-pandemic-methodology/

KFF, 11/23/2021: https://www.kff.org/report-section/kff-covid-19-vaccine-monitor-november2021-methodology/

NHIS: https://nhis.ipums.org/nhis/userNotes_sampledesign.shtml (Source: https://nhis.ipums.org/nhis/ )

NIS-Child: https://www.cdc.gov/vaccines/imz-managers/coverage/childvaxview/datasource.html (Source: https://www.cdc.gov/vaccines/imzmanagers/coverage/childvaxview/pubs-presentations.html) 
Pew, 5/12/2009: Based on telephone interviews conducted under the direction of Princeton Survey Research Associates International among a nationwide sample of 2,001 adults, 18 years of age or older, from April 28 to May 12, 2009 (1,500 respondents were interviewed on a landline telephone, and 501 were interviewed on a cell phone, including 198 who had no landline telephone). Both the landline and cell phone samples were provided by Survey Sampling International. Interviews were conducted in English and Spanish. For detailed information about our survey methodology, see http://peoplepress.org/methodology/. The combined landline and cell phone sample are weighted using an iterative technique that matches gender, age, education, race/ethnicity, region, and population density to parameters from the March 2008 Census Bureau's Current Population Survey. The sample is also weighted to match current patterns of telephone status and relative usage of landline and cell phones (for those with both), based on extrapolations from the 2008 National Health Interview Survey. The weighting procedure also accounts for the fact that respondents with both landline and cell phones have a greater probability of being included in the sample. The error attributable to sampling that would be expected at the $95 \%$ level of confidence for the total sample is 2.5 percentage points.

Pew, 8/25/2014: Conducted by telephone with a national sample of adults (18 years of age or older) living in all 50 U.S. states and the District of Columbia. The results reported here are based on 2,002 interviews (801 respondents were interviewed on a landline telephone and 1,201 were interviewed on a cell phone). Interviews were completed in English and Spanish by live, professionally trained interviewing staff at Princeton Data Source under the direction of Princeton Survey Research Associates International from August 15 to 25, 2014. Survey Design A combination of landline and cell random digit dial (RDD) samples was used to reach a representative sample of all adults in the United States who have access to either a landline or cellular telephone. Both samples were disproportionately stratified to increase the incidence of African-American and Hispanic respondents. Within each stratum, phone numbers were drawn with equal probabilities. The landline samples were list-assisted and drawn from active blocks containing one or more residential listings, while the cell samples were not list-assisted but were drawn through a systematic sampling from dedicated wireless 100-blocks and shared service 100- blocks with no directory-listed landline numbers. Both the landline and cell RDD samples were disproportionately stratified by county based on estimated incidences of African-American and Hispanic respondents. Margin of Sampling Error: Statistical results are weighted to correct known demographic discrepancies, including disproportionate stratification of the sample. The margin of error for the entire sample is \pm 3.1 percentage points.

PSRA, 3/3/1991: Survey Organization: Princeton Survey Research Associates; Survey Sponsor: Troika Productions; Lifetime Television; Study Date: February 28, 1991 - March 3, 1991; Sample: National adult; Sample Size: 600; Geographic Coverage: United States; Interview Method: Telephone interview.

Research!America, 11/2008: Conducted by Charlton Research Company on behalf of Research!America in November 2008 among 800 adults in the U.S. Telephone (randomdigit dialing) polls are conducted with a sample size of 800-1000 adults (age 18+) and a 
maximum theoretical sampling error of $+/-3.5$ percent. Data are demographically representative of adult U.S. residents. (Source: https://www.researchamerica.org/)

Research!America, 5/2018: This nationwide online survey was conducted by Zogby Analytics on behalf of Research!America in May 2018 among 1,004 adults in the U.S. This survey has a theoretical sampling error of $+/-3.1$ percentage points. (Source: https://www.researchamerica.org/sites/default/files/MAY182018 VaccinePressRelease f inal.pdf)

Research!America, 1/2020: This online survey was conducted by Zogby Analytics on behalf of Research! America in January 2020, among 1,003 adults. The survey has a theoretical sampling error of $+/-3.1$ percentage points. (Source: click here.)

Research!America, 8/2020: This online survey was conducted by Zogby Analytics on behalf of Research!America in August 2020, among 1,025 adults plus 869 additional adults for minority oversampling. The survey was supported in part by the Kavli Foundation as a component of support for a working group formed to assess America's commitment to science. For the national sample, the survey has a theoretical sampling error of $+/-3.1$ percentage points. (Source: https://www.researchamerica.org/sites/default/files/ReleaseDeckAugSurvey1008205.pdf)

Roper, 8/23/1976: Study Date: August 28, 1976 - September 4, 1976; Sample: National adult; Sample Size: 1998; Geographic Coverage: United States; Interview Method: Face-to-face interview.

YouGov, 10/27/2009: https://today.yougov.com/about/panel-methodology/ (Source: https://today.yougov.com/topics/politics/explore/topic/The_Economist_YouGov_polls?c ontent=surveys)

YouGov, 2/2/2015: Sponsorship: The Economist; Fieldwork: YouGov; Interviewing Dates: January 31-February 2, 2015; Target population: U.S. citizens, aged 18 and over. Sampling method: Respondents were selected from YouGov's opt-in Internet panel using sample matching. A random sample (stratified by age, gender, race, education, and region) was selected from the 2010 American Community Study. Voter registration was imputed from the November 2010 Current Population Survey Registration and Voting Supplement. Religion, political interest, minor party identification, and non-placement on an ideology scale, were imputed from the 2008 Pew Religion in American Life Survey. Weighting: The sample was weighted using propensity scores based on age, gender, race, education, news interest, voter registration, and non-placement on an ideology scale. The weights range from 0.1 to 4.1 , with a mean of one and a standard deviation of 0.85 . Number of respondents: 1000; Margin of error $\pm 4.1 \%$ (adjusted for weighting). (Source: https://today.yougov.com/topics/politics/explore/topic/The Economist YouGov polls?c ontent=surveys)

YouGov, 1/17/2018: https://today.yougov.com/about/panel-methodology/; (Source: https://today.yougov.com/topics/health/survey-results/daily/2018/01/17/89fda/2)

YouGov, 5/22/2020: The Yahoo News survey was conducted by YouGov using a nationally representative sample of 1,640 U.S. adult residents interviewed online between May 20 and 21,2020. This sample was weighted according to gender, age, race and education, as 
well as 2016 presidential vote, registration status and news interest. Respondents were selected from YouGov's opt-in panel to be representative of all U.S residents. The margin of error is approximately 3.0 percent. (Source: https://www.yahoo.com/now/newyahoo-news-you-gov-poll-shows-coronavirus-conspiracy-theories-spreading-on-theright-may-hamper-vaccine-efforts-152843610.html)

YouGov, 7/21/2020: The Yahoo News survey was conducted by YouGov using a nationally representative sample of 1,525 U.S. adult residents interviewed online between June 29 and July 1, 2020. This sample was weighted according to gender, age, race, and education, as well as 2016 Presidential vote, registration status, geographic region, and news interest. Respondents were selected from YouGov's opt-in panel to be representative of all U.S residents. The margin of error is approximately 3.2 percent. (Source: https://www.yahoo.com/now/yahoo-news-you-gov-july-4th-poll-62-percent-ofamericans-no-longer-see-america-as-shining-city-on-a-hill-202931706.html)

YouGov, 8/4/2020: Sponsorship: The Economist; Fieldwork: YouGov; Interviewing Dates: August 2 - 4, 2020; Target population: US Adult Population; Sampling method:

Respondents were selected from YouGov's opt-in Internet panel using sample matching. A random sample (stratified by gender, age, race, education, and region) was selected from the 2016 American Community Study. Voter registration was imputed from the November 2016 Current Population Survey Registration and Voting Supplement. Weighting: The sample was weighted based on gender, age, race, education, and 2016 Presidential vote (or non-vote). The weights range from 0.201 to 6.531 , with a mean of one and a standard deviation of 0.816. Number of respondents: 1500, 1229 (Registered voters); Margin of error: $\pm 3.3 \%$ (adjusted for weighting). (Source: https://docs.cdn.yougov.com/rz91 tredfv/econToplines.pdf)

YouGov, 10/5/2021: https://today.yougov.com/about/panel-methodology/; (Source: https://docs.cdn.yougov.com/dn9ucep8dl/econTabReport.pdf)

YouGov, 10/12/2021: Sponsorship: The Economist; Fieldwork: YouGov; Interviewing Dates: October 9 - 12, 2021; Target population: US Adult Population; Sampling method: Respondents were selected from YouGov's opt-in Internet panel using sample matching. A random sample (stratified by gender, age, race, education, and region) was selected from the 2018 American Community Study. Voter registration was imputed from the November 2018 Current Population Survey Registration and Voting Supplement. Weighting The sample was weighted based on gender, age, race, education, and both 2016 and 2020 Presidential votes (or non-votes). The weights range from 0.27 to 6.03 , with a mean of one and a standard deviation of 0.605. Number of respondents 15001266 (Registered voters) Margin of error $\pm 3 \%$ (adjusted for weighting). (Source: https://docs.cdn.yougov.com/t7nidivhxp/econToplines.pdf) 


\section{Supplementary Tables}

Table 1.1 How much have you, personally, heard about the advantages of vaccinations for children--a great deal, fair amount, only a little, or nothing at all? (Gallup)

$\begin{array}{lrrr}\text { Adults } & \underline{7 / 1 / 2001} & \frac{3 / 1 / 2015}{12 / 15 / 2019} \\ \text { great deal } & 38 \% & 49 \% & 57 \% \\ \text { fair amount } & 36 \% & 34 \% & 32 \% \\ \text { only a little } & 17 \% & 13 \% & 8 \% \\ \text { nothing at all } & 9 \% & 4 \% & 3 \% \\ \mathrm{dk} / \mathrm{rf} & 1 \% & 1 \% & 0 \% \\ \mathrm{~N} & 494 & 503 & 489\end{array}$

Table 1.2 How much have you, personally, heard about the possible disadvantages of vaccinations for children--a great deal, fair amount, only a little, or nothing at all? (Gallup)

\section{Adults}

great deal

fair amount

only a little

nothing at all

$\mathrm{dk} / \mathrm{rf}$

$\mathrm{N}$

\begin{tabular}{rrr}
\hline$/ 1 / 2001$ & $\frac{3 / 1 / 2015}{15 \%}$ & $12 / 15 / 2019$ \\
$24 \%$ & $30 \%$ & $39 \%$ \\
$32 \%$ & $18 \%$ & $40 \%$ \\
$28 \%$ & $9 \%$ & $17 \%$ \\
$0 \%$ & $1 \%$ & $3 \%$ \\
494 & 512 & $0 \%$ \\
& & 536
\end{tabular}


Table 2.1 Thinking about the common vaccines available today such as polio, tetanus, measles, and flu, how important do you believe vaccines are to the health of our society today?

(Research!America)

\begin{tabular}{lrrrr} 
Adults & Nov-08 & & May-18 & Jan-20 \\
\cline { 2 - 2 } very important & $80 \%$ & $70 \%$ & $71 \%$ \\
somewhat important & $17 \%$ & $22 \%$ & $21 \%$ \\
not very important & $2 \%$ & $4 \%$ & $3 \%$ \\
not at all important & $1 \%$ & $2 \%$ & $2 \%$ \\
dk/rf & $0 \%$ & $2 \%$ & $4 \%$ \\
N & 800 & 1004 & 1003
\end{tabular}

Table 2.2 Do you believe that you have personally benefited from the development of vaccines over the last 50 years? (Research!America)

\begin{tabular}{|c|c|c|c|}
\hline Adults & $\underline{\text { Nov-08 }}$ & May-18 & Aug-20 \\
\hline strongly, yes & $75 \%$ & $59 \%$ & $49 \%$ \\
\hline somewhat, yes & $15 \%$ & $28 \%$ & $27 \%$ \\
\hline somewhat, no & $5 \%$ & $4 \%$ & $11 \%$ \\
\hline strongly, no & $3 \%$ & $5 \%$ & $4 \%$ \\
\hline $\mathrm{dk} / \mathrm{rf}$ & $2 \%$ & $5 \%$ & $8 \%$ \\
\hline$N$ & 800 & 1004 & 1025 \\
\hline
\end{tabular}

Table 3.1 How important do you believe it is for parents to have their children vaccinated? (Research!America)

\begin{tabular}{|c|c|c|c|}
\hline Adults & Nov-08 & May-18 & $\underline{\text { Jan-20 }}$ \\
\hline very important & $82 \%$ & $71 \%$ & $69 \%$ \\
\hline somewhat important & $14 \%$ & $19 \%$ & $18 \%$ \\
\hline not very important & $2 \%$ & $4 \%$ & $4 \%$ \\
\hline not at all important & $1 \%$ & $3 \%$ & $3 \%$ \\
\hline $\mathrm{dk} / \mathrm{rf}$ & $1 \%$ & $3 \%$ & $5 \%$ \\
\hline $\mathrm{N}$ & 800 & 1004 & 1003 \\
\hline
\end{tabular}


Table 3.2 How important is it that parents get their children vaccinated--extremely important, very important, somewhat important, not very important, or not at all important?

(Gallup)

Adults

extremely important

very important

somewhat important

not very important

not at all important

$\mathrm{dk} / \mathrm{rf}$

$\mathrm{N}$

$\begin{array}{rrr}\frac{7 / 1 / 2001}{64 \%} & \frac{3 / 1 / 2015}{12 / 15 / 2019} \\ 30 \% & 54 \% & 58 \% \\ 5 \% & 31 \% & 26 \% \\ 1 \% & 2 \% & 9 \% \\ 1 \% & 2 \% & 2 \% \\ 1 \% & 2 \% & 4 \% \\ 1,014 & 1,015 & 1,025\end{array}$

Table 4 How important is it that parents get their children vaccinated--extremely important, very important, somewhat important, not very important, or not at all important? (Gallup)

\begin{tabular}{|c|c|c|c|c|c|c|c|}
\hline Democrat & $7 / 1 / 2001$ & $\underline{3 / 1 / 2015}$ & $\underline{12 / 15 / 2019}$ & Republican & $7 / 1 / 2001$ & $\underline{3 / 1 / 2015}$ & $12 / 15 / 2019$ \\
\hline extremely important & $67 \%$ & $62 \%$ & $70 \%$ & extremely important & $60 \%$ & $53 \%$ & $52 \%$ \\
\hline very important & $29 \%$ & $26 \%$ & $22 \%$ & very important & $33 \%$ & $29 \%$ & $27 \%$ \\
\hline somewhat important & $2 \%$ & $9 \%$ & $6 \%$ & somewhat important & $7 \%$ & $16 \%$ & $11 \%$ \\
\hline not very important & $0 \%$ & $0 \%$ & $0 \%$ & not very important & $0 \%$ & $0 \%$ & $3 \%$ \\
\hline not at all important & $0 \%$ & $2 \%$ & $2 \%$ & not at all important & $0 \%$ & $1 \%$ & $5 \%$ \\
\hline $\mathrm{dk} / \mathrm{rf}$ & $1 \%$ & $1 \%$ & $0 \%$ & $\mathrm{dk} / \mathrm{rf}$ & $0 \%$ & $1 \%$ & $1 \%$ \\
\hline $\mathrm{N}$ & 336 & 312 & 303 & $\mathrm{~N}$ & 336 & 277 & 316 \\
\hline
\end{tabular}


Table 5.1 In general, how confident are you in the safety of vaccines used today? (Research!America)

\begin{tabular}{|c|c|c|c|c|}
\hline Adults & Nov-08 & May-18 & $\underline{\operatorname{Jan}-20}$ & Aug-20 \\
\hline very confident & $46 \%$ & $35 \%$ & $44 \%$ & $41 \%$ \\
\hline somewhat confident & $44 \%$ & $46 \%$ & $37 \%$ & $31 \%$ \\
\hline not too confident & $7 \%$ & $11 \%$ & $9 \%$ & $15 \%$ \\
\hline not at all confident & $2 \%$ & $6 \%$ & $5 \%$ & $6 \%$ \\
\hline not sure & $1 \%$ & $2 \%$ & $5 \%$ & $7 \%$ \\
\hline $\mathrm{N}$ & 800 & 1004 & 1003 & 1025 \\
\hline
\end{tabular}

Table 5.2 "Do you think vaccines are more dangerous than the diseases they are designed to prevent, or not?" (Gallup)

$\begin{array}{lrrr}\text { Adults } & \underline{7 / 1 / 2001} & \underline{3 / 1 / 2015} & \frac{12 / 15 / 2019}{11.4 \%} \\ \text { yes } & 5.9 \% & 8.7 \% & 11.4 \% \\ \text { no } & 90.3 \% & 87.4 \% & 86.4 \% \\ \text { dk/rf } & 3.8 \% & 3.9 \% & 2.0 \% \\ \text { N } & 1014 & 1015 & 1025\end{array}$

Table 6 Do you think vaccines are more dangerous than the diseases they are designed to prevent, or not? (Gallup)

$\begin{array}{lrrrlrrr}\text { Democrat } & \underline{7 / 1 / 2001} & \frac{3 / 1 / 2015}{12 / 15 / 2019} & & \text { Republican } & \underline{7 / 1 / 2001} & \underline{3 / 1 / 2015} & \underline{12 / 15 / 2019} \\ \text { yes } & 4.3 \% & 9.1 \% & 7.2 \% & \text { yes } & 5.5 \% & 6.8 \% & 12.7 \% \\ \text { no } & 92.2 \% & 88.3 \% & 90.4 \% & \text { no } & 91.2 \% & 89.9 \% & 84.5 \% \\ \text { dk/rf } & 3.5 \% & 2.5 \% & 2.1 \% & \text { dk/rf } & 3.4 \% & 3.3 \% & 2.8 \% \\ \text { N } & 336 & 312 & 303 & & 336 & 277 & 316\end{array}$


Table 7.1 In general, how safe are vaccines given to children for diseases like measles, mumps, and rubella-very safe, somewhat safe, not very safe, or not safe at all? (CBS; YouGov)

\section{Adults \\ very safe \\ somewhat safe \\ not very safe \\ not safe at all \\ $\mathrm{dk} / \mathrm{na}$}

$\mathrm{N}$

*YouGov fielded the same question multiple times in this month;

\begin{tabular}{|c|c|c|c|c|}
\hline CBS & YouGov & YouGov & YouGov & YouGov* \\
\hline $2 / 17 / 2015$ & $5 / 22 / 2020$ & $7 / 21 / 2020$ & $8 / 4 / 2020$ & $10 / 12 / 2021$ \\
\hline $61.5 \%$ & $48.0 \%$ & $49 \%$ & $52 \%$ & $56 \%$ \\
\hline $28.3 \%$ & $35.0 \%$ & $35 \%$ & $34 \%$ & $30 \%$ \\
\hline $4.1 \%$ & $11.0 \%$ & $10 \%$ & $9 \%$ & $8 \%$ \\
\hline $1.7 \%$ & $6.0 \%$ & $5 \%$ & $5 \%$ & $6 \%$ \\
\hline $4.5 \%$ & & & & \\
\hline 1006 & 1637 & 1492 & 1488 & 1494 \\
\hline
\end{tabular}

Table 8 In general, how safe are vaccines given to children for diseases like measles, mumps, and rubella-very safe, somewhat safe, not very safe, or not safe at all? (CBS; YouGov)

\begin{tabular}{|c|c|c|c|c|c|c|c|c|c|c|c|}
\hline & CBS & YG & YG & YG & YG* & & CBS & YG & YG & YG & YG* \\
\hline & $2 / 17 /$ & $5 / 22 /$ & $7 / 21 /$ & $8 / 4 /$ & $10 / 12 /$ & & $2 / 17 /$ & $5 / 221$ & $7 / 21 /$ & $8 / 4 /$ & $10 / 12 /$ \\
\hline Democrat & $\underline{2015}$ & $\underline{2020}$ & $\underline{2020}$ & 2020 & 2021 & Republican & $\underline{2015}$ & $\underline{2020}$ & 2020 & 2020 & 2021 \\
\hline very safe & $69.6 \%$ & $56 \%$ & $56 \%$ & $63 \%$ & $72 \%$ & very safe & $61.9 \%$ & $46 \%$ & $47 \%$ & $47 \%$ & $47 \%$ \\
\hline somewhat safe & $25.1 \%$ & $31 \%$ & $33 \%$ & $26 \%$ & $20 \%$ & somewhat safe & $27.5 \%$ & $36 \%$ & $37 \%$ & $38 \%$ & $35 \%$ \\
\hline not very safe & $2.3 \%$ & $9 \%$ & $9 \%$ & $7 \%$ & $8 \%$ & not very safe & $3.4 \%$ & $9 \%$ & $11 \%$ & $11 \%$ & $9 \%$ \\
\hline not safe at all & $1.0 \%$ & $3 \%$ & $3 \%$ & $4 \%$ & $0 \%$ & not safe at all & $3.8 \%$ & $9 \%$ & $5 \%$ & $4 \%$ & $8 \%$ \\
\hline $\mathrm{dk} / \mathrm{na}$ & $2.0 \%$ & & & & & $\mathrm{dk} / \mathrm{na}$ & $3.4 \%$ & & & & \\
\hline $\mathrm{N}$ & 305 & 556 & 531 & 499 & 496 & $\mathrm{~N}$ & 255 & 421 & 388 & 402 & 392 \\
\hline
\end{tabular}

*YouGov fielded the same question multiple times in this month; only the first iteration in the month is recorded here. 
Table 9.1 Thinking about childhood diseases, such as measles, mumps, rubella and polio...should parents be able to decide not to

vaccinate their children or should all children be required to be vaccinated? (Pew)

\begin{tabular}{|c|c|c|}
\hline Adults & $\underline{5 / 12 / 2009}$ & $\underline{8 / 25 / 2014}$ \\
\hline parental decision & $27.6 \%$ & $30.1 \%$ \\
\hline require vaccination & $69.4 \%$ & $68.5 \%$ \\
\hline $\mathrm{dk}(\mathrm{vol}.) / \mathrm{rf}$ & $3.0 \%$ & $1.4 \%$ \\
\hline $\mathrm{N}$ & 2,001 & 2,002 \\
\hline
\end{tabular}

Table 9.2 Do you think the government should or should not require parents have their children vaccinated against infectious diseases (e.g. measles, mumps, whooping cough)? (YouGov 2015) / Do you think parents should be required to have their children vaccinated against infectious diseases? (YouGov 2020-21)

\begin{tabular}{|c|c|c|c|c|c|}
\hline Adults & $2 / 2 / 2015$ & $\underline{5 / 21 / 2020}$ & $\underline{7 / 21 / 2020}$ & $\underline{8 / 4 / 2020 *}$ & $10 / 12 / 2021^{*}$ \\
\hline should & $68 \%$ & $68 \%$ & $65 \%$ & $64 \%$ & $60 \%$ \\
\hline should not & $18 \%$ & $15 \%$ & $19 \%$ & $19 \%$ & $23 \%$ \\
\hline not sure & $14 \%$ & $17 \%$ & $16 \%$ & $17 \%$ & $17 \%$ \\
\hline $\mathrm{N}$ & 998 & 1,634 & 1,492 & 1,496 & 1,494 \\
\hline
\end{tabular}

*YouGov fielded the same question multiple times in this month; only the first iteration in the month is recorded here. 
Table 9.3 Do you think the government should require all parents to have their children vaccinated against contagious diseases such as measles, or do you think that's something the government should stay out of? (PSRA; Gallup)

\begin{tabular}{|c|c|c|}
\hline & PSRA & Gallup \\
\hline Adults & $\underline{3 / 3 / 1991}$ & $\underline{12 / 15 / 2019}$ \\
\hline government require & $81 \%$ & $62 \%$ \\
\hline government stay out & $14 \%$ & $35 \%$ \\
\hline it depends (vol.) & $3 \%$ & $2 \%$ \\
\hline $\mathrm{dk} / \mathrm{rf}$ & $2 \%$ & $1 \%$ \\
\hline $\mathrm{N}$ & 600 & 1025 \\
\hline
\end{tabular}

Table 10.1 Thinking about childhood diseases, such as measles, mumps, rubella and polio...should parents be able to decide not to vaccinate their children or should all children be required to be vaccinated? (Pew)

$\begin{array}{lrr}\text { Democrat } & 5 / 12 / 2009 & \\ \text { parental decision } & 27.1 \% & 22.1 \% \\ \text { require vaccination } & 70.9 \% & 76.5 \% \\ \mathrm{dk} / \mathrm{rf} \text { (vol.) } & 1.9 \% & 1.4 \% \\ \mathrm{~N} & 747 & 666\end{array}$

Republican
parental decision
require vaccination
$\mathrm{dk} / \mathrm{rf}$ (vol.)
$\mathrm{N}$

$5 / 12 / 2009$

$25.7 \%$

$70.7 \%$

$3.6 \%$

504
$8 / 25 / 2014$

$33.9 \%$

$65.1 \%$

$1.0 \%$ 454 
Table 10.2 Do you think the government should or should not require parents have their children vaccinated against infectious diseases (e.g. measles, mumps, whooping cough)? (YouGov 2015)/Do you think parents should be required to have their children vaccinated against infectious diseases? (YouGov 2020-21)

\begin{tabular}{|c|c|c|c|c|c|c|c|c|c|c|c|}
\hline & $2 / 2 /$ & $5 / 21 /$ & 7/21/ & $8 / 4 /$ & $10 / 12 /$ & & $2 / 2 /$ & 5/21/ & 7/21/ & $8 / 4 /$ & $10 / 12 /$ \\
\hline Democrat & $\underline{2015}$ & $\underline{2020}$ & $\underline{2020}$ & $\underline{2020^{*}}$ & $\underline{2021^{*}}$ & Republican & $\underline{2015}$ & $\underline{2020}$ & $\underline{2020}$ & $\underline{2020^{*}}$ & $\underline{2021^{*}}$ \\
\hline should & $81 \%$ & $79 \%$ & $76 \%$ & $79 \%$ & $85 \%$ & should & $67 \%$ & $64 \%$ & $61 \%$ & $58 \%$ & $46 \%$ \\
\hline should not & $5 \%$ & $8 \%$ & $14 \%$ & $10 \%$ & $8 \%$ & should not & $22 \%$ & $18 \%$ & $24 \%$ & $27 \%$ & $35 \%$ \\
\hline not sure & $14 \%$ & $12 \%$ & $10 \%$ & $11 \%$ & $8 \%$ & not sure & $11 \%$ & $18 \%$ & $15 \%$ & $15 \%$ & $20 \%$ \\
\hline$N$ & 356 & 554 & 529 & 500 & 497 & $\mathrm{~N}$ & 241 & 419 & 388 & 403 & 391 \\
\hline
\end{tabular}

*YouGov fielded the same question multiple times in this month; only the first iteration in the month is recorded here. 
Table 11.1 [Estimated MMR vaccination rate for children 19-35 months, derived from National Immunization Survey-Child. See Survey Methods section of this appendix for additional details.]

\begin{tabular}{ll}
$\underline{\text { Year }}$ & Vaccinated \\
\cline { 2 - 2 } 1994 & $89.0 \%$ \\
1995 & $90.0 \%$ \\
1996 & $91.0 \%$ \\
1997 & $88.5 \%$ \\
1998 & $86.0 \%$ \\
1999 & $92.0 \%$ \\
2000 & $91.0 \%$ \\
2001 & $91.4 \%$ \\
2002 & $91.6 \%$ \\
2003 & $93.0 \%$ \\
2004 & $93.0 \%$ \\
2005 & $91.5 \%$ \\
2006 & $92.3 \%$ \\
2007 & $92.3 \%$ \\
2008 & $92.1 \%$ \\
2009 & $90.0 \%$ \\
2010 & $91.5 \%$ \\
2011 & $91.6 \%$ \\
2012 & $90.8 \%$ \\
2013 & $91.9 \%$ \\
2014 & $91.5 \%$ \\
2015 & $91.9 \%$ \\
2016 & $91.1 \%$ \\
2017 & $91.5 \%$
\end{tabular}


Table 11.2 To the best of your recollection, did you have your children vaccinated against diseases such as measles, mumps, and rubellaor not? (CBS; asked of parents)

\begin{tabular}{|c|c|c|c|c|c|}
\hline Parents & $2 / 17 / 2015$ & Democrat & $\underline{2 / 17 / 2015}$ & Republican & $\underline{2 / 17 / 2015}$ \\
\hline yes & $92.0 \%$ & yes & $94 \%$ & yes & $98 \%$ \\
\hline no & $5.0 \%$ & no & $4 \%$ & no & $2 \%$ \\
\hline some, not others & $1.0 \%$ & some, not others & $0 \%$ & some, not others & $0 \%$ \\
\hline too young & $1.0 \%$ & too young & $2 \%$ & too young & $0 \%$ \\
\hline $\mathrm{dk} / \mathrm{na}$ & $1.0 \%$ & $\mathrm{dk} / \mathrm{na}$ & $1 \%$ & $\mathrm{dk} / \mathrm{na}$ & $0 \%$ \\
\hline $\mathrm{N}$ & 1,006 & $\mathrm{~N}$ & 300 & $\mathrm{~N}$ & 255 \\
\hline
\end{tabular}

Table 11.3 Do you normally keep your children up-to-date with recommended childhood vaccines such as the MMR vaccine, or have you ever delayed or skipped some childhood vaccines for your children? (KFF; asked of parents or guardians with a child living in the household)

$\begin{array}{lrrlrrlrr}\text { Parents } & 8 / 2 / 2021 & 11 / 23 / 2021 & \text { Democrat } & \underline{8 / 2 / 2021} & 11 / 23 / 2021 & \text { Republican } & \frac{8 / 2 / 2021}{11 / 23 / 2021} & \frac{11 / 2}{87.02} \\ \text { yes } & 90.4 \% & 89.6 \% & \text { yes } & 93.1 \% & 95.9 \% & \text { yes } & 88 \% & 87.0 \% \\ \text { no } & 8.9 \% & 8.7 \% & \text { no } & 6.9 \% & 3.8 \% & \text { no } & 11 \% & 9.8 \% \\ \text { dk/na } & 0.7 \% & 1.7 \% & \text { dk/na } & 0.0 \% & 0.3 \% & \text { dk/na } & 1 \% & 3.2 \% \\ \text { N } & 1259 & 1196 & \mathrm{~N} & 473 & 398 & \mathrm{~N} & 189 & 235\end{array}$

Table 12.1 Last year, did you get a flu shot? (2009) / Have you gotten a flu shot this season? (2018) / Did you get the influenza vaccine (flu shot) last year in 2020? (2021) (all polls: YouGov)

$\begin{array}{lrrr}\text { Adults } & 10 / 27 / 2009 & 1 / 17 / 2018 & 10 / 5 / 2021 \\ \text { yes } & 37.7 \% & 45 \% & 49 \% \\ \text { no } & 61.3 \% & 52 \% & 46 \% \\ \text { not sure } & 1.0 \% & 3 \% & 5 \% \\ \text { N } & 996 & 5814 & 1498\end{array}$


DURING THE PAST 12 MONTHS, have you had a flu vaccination? A flu vaccination is

usually given in the fall and protects

Table 12.2 against influenza for the flu season. (NHIS)

$\begin{array}{llll}\text { Year } & \text { yes } & \text { no } & \underline{\mathrm{N}} \\ 2005 & 21.4 \% & 78.6 \% & 30,830 \\ 2006 & 27.5 \% & 72.5 \% & 23,833 \\ 2007 & 30.1 \% & 69.9 \% & 22,843 \\ 2008 & 32.6 \% & 67.4 \% & 21,340 \\ 2009 & 34.6 \% & 65.4 \% & 27,354 \\ 2010 & 35.6 \% & 64.4 \% & 26,538 \\ 2011 & 37.8 \% & 62.2 \% & 32,517 \\ 2012 & 37.6 \% & 62.4 \% & 33,732 \\ 2013 & 40.9 \% & 59.1 \% & 33,934 \\ 2014 & 42.1 \% & 57.9 \% & 35,979 \\ 2015 & 43.1 \% & 56.9 \% & 32,968 \\ 2016 & 42.2 \% & 57.8 \% & 32,471 \\ 2017 & 43.4 \% & 56.6 \% & 26,291 \\ 2018 & 44.6 \% & 55.4 \% & 25,045 \\ 2019 & 46.8 \% & 53.2 \% & 31,541 \\ 2020 & 47.9 \% & 52.1 \% & 31,155\end{array}$

Table 13.1 Last year, did you get a flu shot? (2009) / Have you gotten a flu shot this season? (2018) / Did you get the influenza vaccine (flu shot) last year in 2020? (2021) (all polls: YouGov)

\begin{tabular}{|c|c|c|c|c|c|c|c|}
\hline Democrat & $\underline{10 / 27 / 2009}$ & $\underline{1 / 17 / 2018}$ & $10 / 5 / 2021$ & Republican & $10 / 27 / 2009$ & $\underline{1 / 17 / 2018}$ & $10 / 5 / 2021$ \\
\hline yes & $38.3 \%$ & $51 \%$ & $64 \%$ & yes & $39.5 \%$ & $46 \%$ & $50 \%$ \\
\hline no & $60.8 \%$ & $47 \%$ & $34 \%$ & no & $60.1 \%$ & $52 \%$ & $49 \%$ \\
\hline not sure & $0.9 \%$ & $2 \%$ & $3 \%$ & not sure & $0.5 \%$ & $2 \%$ & $2 \%$ \\
\hline $\mathrm{N}$ & 381 & NA & 504 & $\mathrm{~N}$ & 243 & NA & 393 \\
\hline
\end{tabular}


Table 14.1 Would you like to take this new polio vaccine (to keep people from getting polio) yourself? (Gallup; asked of those who had heard/read about the vaccine [92\%])

$\begin{array}{lrrrr} & \underline{5 / 7 / 1954} & \frac{5 / 7 / 1954}{1} & \frac{5 / 7 / 1954}{\text { Adults }} & \frac{\text { Democrat }}{\text { Republican }} \\ \text { yes } & 60 \% & 62 \% & 59 \% \\ \text { no } & 31 \% & 30 \% & 33 \% \\ \text { no opinion } & 9 \% & 8 \% & 8 \% \\ \text { N } & 1293 & 571 & 391\end{array}$

Table 14.2 IF A VACCINE BECOMES AVAILABLE, DO YOU PLAN TO TAKE SHOTS TO PROTECT AGAINST THIS [Asian] FLU, OR NOT? (Gallup; asked of those who heard/read about Asian flu [92\%])

\begin{tabular}{|c|c|c|}
\hline $9 / 4 / 1957$ & $9 / 4 / 1957$ & $9 / 4 / 1957$ \\
\hline Adults & Democrat & Republican \\
\hline $65 \%$ & $70 \%$ & $62 \%$ \\
\hline $20 \%$ & $16 \%$ & $22 \%$ \\
\hline $0 \%$ & $1 \%$ & $0 \%$ \\
\hline $15 \%$ & $14 \%$ & $16 \%$ \\
\hline 1401 & 594 & 465 \\
\hline
\end{tabular}

Table 14.3 There has been a lot of talk about the possibility this winter of a swine flu epidemic like the one that killed so many people in 1918. The government has set up a program for mass inoculations for the public against swine flu to be financed out of tax revenues. Do you think you personally will get an inoculation against swine flu this fall or not? (Roper)

\section{8/23/1976 8/23/1976 8/23/1976}

Adults Democrat Republican

yes

$54 \%$

$57 \%$

$53 \%$

no

$30 \%$

$28 \% \quad 30 \%$

$\mathrm{dk}$

$16 \%$

$16 \%$

$17 \%$

$\mathrm{N}$

1998

926

418 
Table 14.4 Would you, personally, get a smallpox vaccine if it were available? (Gallup)

$\begin{array}{lrrrr} & \frac{11 / 14 / 2002}{} & \frac{11 / 14 / 2002}{\text { Adults }} & \frac{11 / 14 / 2002}{\text { Democrat }} & \frac{\text { Republican }}{4} \\ \text { yes } & 55 \% & 60 \% & 49 \% \\ \text { no } & 35 \% & 31 \% & 40 \% \\ \text { dk/rf } & 9 \% & 9 \% & 11 \% \\ \text { N } & 475 & 141 & 161\end{array}$

Table 14.5 Suppose a vaccine for the swine flu virus is developed later this year (2009). Do you think you, personally, would or would not get this vaccine? (Gallup)

\begin{tabular}{|c|c|c|c|}
\hline & $\underline{10 / 27 / 2009}$ & $10 / 27 / 2009$ & $10 / 27 / 2009$ \\
\hline & Adults & Democrat & Republican \\
\hline yes & $55 \%$ & $62 \%$ & $47 \%$ \\
\hline no & $42 \%$ & $36 \%$ & $51 \%$ \\
\hline $\mathrm{dk} / \mathrm{rf}$ & $3 \%$ & $2 \%$ & $2 \%$ \\
\hline $\mathrm{N}$ & 1014 & 310 & 323 \\
\hline
\end{tabular}

Table 14.6 If an FDA-approved vaccine to prevent coronavirus/COVID-19 was available right now at no cost, would you agree to be vaccinated? (Gallup)

yes

no
Adults

$66 \%$

$34 \%$

3005
$7 / 26 / 2020$

Democrat

$83 \%$

$17 \%$

1214
$7 / 26 / 2020$

Republican $46 \%$ $54 \%$

894 